\title{
¿Qué efectos produce el control de convencionalidad decretado por la Corte Interamericana en un ordenamiento jurídico?
}

\author{
What effects does produces the control of conventionality decreed \\ by the inter-american court in a legal system?
}

\author{
Max Silva Abbotт ${ }^{1}$ \\ Universidad San Sebastián \\ max.silva@uss.cl
}

\begin{abstract}
Resumen: El objeto del presente trabajo es averiguar qué efectos produce la declaración de inconvencionalidad realizada por la Corte Interamericana de Derechos Humanos al interior de un ordenamiento jurídico, en aquellos casos en que la norma impugnada resulta absolutamente incompatible con sus criterios, no siendo posible una armonización entre ambas mediante la llamada "interpretación conforme”. Para ello se analiza la doctrina que ha tratado esta cuestión, así como la jurisprudencia atingente emanada de este tribunal internacional.
\end{abstract}

Palabras clave: Corte Interamericana de Derechos Humanos; Control de convencionalidad externo; Control de convencionalidad interno; Autoridades nacionales; Ordenamiento jurídico.

1 Licenciado en Ciencias Jurídicas y Sociales por la Universidad de Chile (1993). Doctor en Derecho por la Universidad de Navarra (2006). Profesor de Filosofía del Derecho, Fundamentos Filosóficos del Derecho e Introducción al Derecho, Universidad San Sebastián. Director de Carrera de la sede Concepción de la misma universidad.

Artículo recibido el 26.03.2019 y aceptado para su publicación el 29.04.2020. 


\begin{abstract}
The purpose of this paper is to find out what effects the declaration of unconventionality made by the Inter-American Court of Human Rights within a legal system produces, in those cases in which the contested norm is absolutely incompatible with its criteria, not being possible harmonization between them through the so-called "according interpretation". For it, the doctrine that has dealt with this issue is analyzed, as well as the relevant jurisprudence emanating from this international tribunal.
\end{abstract}

Keywords: Inter-American Court of Human Rights; External control of conventionality; Internal contol of conventionality; National authorities; Legal system.

\title{
1. Introducción
}

El presente trabajo tiene por objeto indagar en los efectos que produce la declaración de inconvencionalidad realizada por la Corte Interamericana de Derechos Humanos al interior de un ordenamiento jurídico, en aquellos casos en que la norma impugnada resulta absolutamente incompatible con sus criterios, no siendo posible una armonización entre ambas mediante la llamada "interpretación conforme". Esta última posibilidad no es analizada aquí.

Lo anterior se debe a que al indagar en la abundante doctrina que ha reflexionado sobre este tema, se puede apreciar una notable disparidad de criterios, así como una gran diferencia de nomenclaturas utilizadas a este respecto. Es precisamente la aludida heterogeneidad lo que nos ha llevado a intentar dilucidar esta cuestión, en razón de su crucial importancia para el funcionamiento del Sistema Interamericano de Derechos Humanos.

Para aclarar lo anterior, primero se pasará revista a las diversas aseveraciones que sobre el particular ha hecho la doctrina, mostrando la heterogeneidad señalada. Posteriormente se analizará la jurisprudencia emanada de la Corte Interamericana relacionada a esta cuestión (hasta fines de 2018), tanto aquella procedente de sentencias definitivas como de supervisiones de cumplimiento (abreviadas estas últimas en las notas a pie de página y en la bibliografía con las siglas S.C.). El eje de este análisis será la permanente distinción y mutua relación entre el llamado control de convencionalidad "externo", que es el realizado por la propia Corte Interamericana, y el control de convencionalidad "interno", esto es, el que de acuerdo a este tribunal, debieran realizar las autoridades nacionales. 
Finalmente y luego de hacer una reflexión general a partir de los datos obtenidos, se arribará a algunas conclusiones.

Debe dejarse constancia que en el presente trabajo no se analizan los votos disidentes ni concurrentes emanados de este tribunal. También, que por razones de espacio, el número de citas, tanto de doctrina como de jurisprudencia, se han reducido notablemente.

\section{Análisis doctrinario}

Como se sabe, la Corte ha señalado en varias oportunidades -y la doctrina lo ha comentado profusamente- que la norma inconvencional declarada incompatible con sus criterios, "carece de efectos jurídicos"2, incluso "desde un inicio" ${ }^{3}$. Además, se supone que la declaración de inconvencionalidad debiera tener efectos generales en el país condenado y no sólo en el caso concreto que ha dado origen a dicha condena ${ }^{4}$. Y por último, algunos autores hablan incluso de un control de convencionalidad en abstracto, esto es, que para tener efectos, no se requiere que la norma declarada incompatible haya sido aplicada todavía 5 .

La otra posibilidad, menos drástica, es la llamada "interpretación conforme", esto es, que el sentido y alcance de la normativa nacional sea establecido a la luz del control de convencionalidad realizado por la Corte por medio de su jurisprudencia $^{6}$. Esta interpretación conforme hace innecesario modificar la norma ${ }^{7}$ y permite el "reciclaje del derecho interno". Por eso se ha dicho que el control de convencionalidad puede ser tanto un control normativo como un ejercicio de interpretación ${ }^{9}$. Esta posibilidad no es analizada en el presente trabajo.

\footnotetext{
2 Entre otros muchos, abordan esto, Ferrer Mac-Gregor y Pelayo (2017), pp. 99 y 102; Torelly (2017), pp. 445-446; Ferrer Mac-Gregor (2013), p. 651; Aguilar (2016b), pp. 348-351; Olano (2016), p. 67.

3 Ferrer Mac-Gregor (2010), p. 187; Hitters (2015), p. 145; Jiménez García (2010), p. 100; SagüÉs (2012), p. 22; CARBONELl (s/f), pp. $72-73$.

4 Ferrer MaC-Gregor (2013), pp. 650-651 y 684-685; Ferrer MaC-Gregor (2016a), pp. 14 y 32; Ferrer Mac-Gregor y Pelayo (2017), p. 100; Castilla (2016), p. 116; Hitters (2008), pp. 145-147.

5 Burgorgue-Larsen (2014), p. 429; Rey Cantor (2008), pp. 237 y 261-262; Londoño (2010), pp. 801-802 803; HitTERs (2009), pp. 118-119 y 125.

6 Rousset (2016), p. 46; SagüÉs (2016), p. 112; Ferrer MaC-Gregor (2011b), pp. 939-940; Aguilar (2016a), pp. 133-134; BAZÁn (2010), pp. 172-173.

7 IbáÑez Rivas (2017), pp. 118-119; Burgorgue-Larsen (2014), pp. 431-432.

8 SAGÜÉS (2015a), p. 144; SAGÜÉs (2015b), p. 276.

9 HeNRÍQUEZ Y NÚÑEZ (2016), p. 132.
} 
Ahora bien, si se analiza el tratamiento de la doctrina respecto de qué significa exactamente que la norma objetada carezca de efectos jurídicos (desde un inicio), se aprecia una gran disparidad de criterios, lo cual indica que se trata de un punto poco claro. Incluso, aquellos autores que al final de su análisis llegan a una conclusión cercana a la del presente trabajo, en diversos pasajes de sus escritos utilizan nomenclaturas muy diferentes para referirse a esta cuestión, todo lo cual induce a confusión. A fin de comprender lo anterior, se pasará revista brevemente a las diversas aseveraciones que se han hecho a este respecto.

Para ello, se agruparán las diversas consideraciones que existen sobre el particular en dos grupos: uno que postula una consecuencia "fuerte" de los efectos de la declaración de inconvencionalidad realizada por la Corte en el ordenamiento jurídico nacional y otra que le atribuye una consecuencia "débil". Con todo, en algunos casos hay autores que al menos al tenor de ciertos pasajes en que abordan este tema, pueden ser encasillados en ambas posturas, lo que reafirma nuestra percepción de estar ante un tema poco claro.

a) En primer lugar, existen autores que al abordar el control de convencionalidad que realiza la Corte, lo hacen -al menos en algunos de sus pasajes- de una manera tal, que inducen a pensar que la sola declaración de este tribunal internacional produciría de manera directa, automática e inmediata algún efecto respecto de la norma nacional impugnada. Sin embargo, se aprecia una notable dispersión de nomenclaturas sobre el particular, pues hay autores que hablan de "invalidación"10, de "expulsión"11, de "derogación"12, de "nulidad"13 o de "inaplicación" ${ }^{14}$ de la norma local afectada. Ello, pese a que en muchas oportunidades maticen o desmientan más adelante estas afirmaciones, por ejemplo, respecto de la "invalidación" ${ }^{15}$ o la "anulación"16 de la norma declarada inconvencional. Ahora, más allá de la notable diferencia de nombres que se utilizan para referirse a este tema, lo común a estos pasajes según se ha dicho, es que inducen a pensar que este

10 Fuenzalida (2015), p. 177; Morales (2014), p. 295; Morales (2017), p. 450; Contreras Vásquez (2014), pp. 251-252.

11 Olano (2016), p. 71.

12 García SayÁn (2009), p. 103; Contreras Vásquez (2014), pp. 251-252; IbáÑEz Rivas (2017), pp. 109-110. 13 TORElly (2017), pp. 344 y 347; Hitters (2012), pp. 543-544; Risso (2013), p. 648.

14 Hitters (2009), p. 123; de manera más vaga (al considerar a la Corte Interamericana "una Corte de Casación supranacional en derechos humanos", Fuenzalida (2015), pp. 176-177.

15 Dulitzky (2014), pp. 545-546; Dulitzky (2015), pp. 66-67; SAGÜÉs (s/f a), p. 461; SAGÜÉs (2009a), p. 6; BINDER (2010), pp. 169-170 y 172-173.

16 Desde diferentes perspectivas, Burgorgue-Larsen (2014), pp. 430 y 431 y Mejía (2014), p. 138. 
efecto, sea cual fuere, se produce de manera directa al interior del ordenamiento jurídico nacional por la sola declaración de inconvencionalidad realizada por la Corte Interamericana.

En otros casos, y al margen de quién genere estos efectos (razón por la cual en ciertas oportunidades son autores que corresponden a la letra $b$ ), que se verá en seguida), al explicar qué significa la expresión "carece de efectos jurídicos", las nomenclaturas son nuevamente muy dispares. De esta manera, si bien varios estudiosos distinguen nítidamente entre "invalidez" e "inaplicación”" debe advertirse que algunos, al menos en ciertos pasajes -que muchas veces son contrarrestados por otros del mismo autor-, dan la impresión de hacerlos sinónimos o no distinguen claramente entre $\operatorname{ambos}^{18}$. En otras ocasiones, sea alabando o criticando esta posibilidad, hablan directamente de "invalidez"19. También hay quienes estiman que esta carencia de efectos jurídicos equivale a la "nulidad" (generalmente desde un inicio) de las normas inconvencionales ${ }^{20}$. Igualmente, algunos autores hablan de "expulsión" de la norma objetada del ordenamiento jurídico, diferenciando de manera clara esta posibilidad de otras eventuales consecuencias ${ }^{21}$. Por último, también se ha dicho que "carecen desde un principio de valor y eficacia jurídica"22.

Ahora bien, al margen de su coincidencia -o no- con lo que realmente ocurre, todo lo anterior muestra que no existe consenso en la doctrina, o al menos que la nomenclatura utilizada resulta muy dispar al momento de explicar qué significa que la norma inconvencional "carezca de efectos jurídicos", incluso "desde un inicio".

b) Por otro lado, existen autores que no atribuyen un efecto directo a la declaración de inconvencionalidad que realiza la Corte, si bien tratan este tema desde diferentes perspectivas. Sin embargo, lo común a todas ellas es que se requiere de

17 Ferrer Mac-Gregor (2011a), pp. 388-389, 390 y 395; García Pino y Contreras Vásquez (2014), pp. 217-218; Burgorgue-Larsen (2014), p. 435; García Ramírez (2015), p. 147 (nota 146).

18 Por ejemplo, Contreras Vásquez (2014), pp. 252-253; SagüÉs (2010), pp. 127-128; SagüÉs (2015a), p. 144; IbáñEZ Rivas (2017), p. 119; Morales (2017), p. 450.

19 Dulitzky (2014), pp. 545-546; García Jaramillo (2016), p. 148; SagüÉs (2010), pp. 117, 130 y 133; FueNZALIDA (2015), p. 177; HENRÍQUEZ Viñas (2014), pp. 134 Y 135-136.

20 Ferrer MaC-Gregor (2015), pp. 95-96; Hitters (2012), pp. 543-544; Binder (2010), pp. 169-172; BurGORGUE-LARSEN (2014), pp. 426-427 y 431; RISSO (2013), p. 648.

21 García Pino (2014), p. 372; Castilla (2013), p. 74; Nash (2013), pp. 491-492 y 505; García Ramírez (2016), pp. 181-182; Nogueira (2013a), pp. 546-547. También habla de "expulsión", Carbonell (s/f), p. 87.

22 Nogueira (2012c), p. 68. 
la colaboración de los organismos internos para que las aseveraciones de la Corte tengan efectos.

De esta manera y siguiendo lo establecido por este tribunal, según se verá en el epígrafe siguiente, hay autores que señalan que es el juez nacional quien debe actuar cuando el legislador "falla" en su tarea de protección de los derechos humanos, evitando así que el Estado caiga en responsabilidad internacional ${ }^{23}$. La idea es así que los "los jueces velen porque los efectos de las disposiciones de la Convención Americana no se vean mermados por la aplicación de leyes contrarias a su objeto y fin"24, para no comprometer al Estado. Se produce así un desplazamiento desde la labor que debiera realizar el poder legislativo al poder judicial ${ }^{25}$. Ello, porque los jueces nacionales tienen un papel preponderante en el cumplimiento de los fallos de la Corte ${ }^{26}$. Por eso,

"Los jueces nacionales pueden y deben tener una actitud activa de cooperación y de coordinación voluntaria con la CIDH, donde el juez nacional no solamente buscará comprender el espíritu de las soluciones jurisprudenciales emitidas por la CIDH, sino que asume un rol activo de interpretación y aplicación de la Convención en derecho interno." ${ }^{27}$

En consecuencia, y siempre que tenga competencia para ello ${ }^{28}$, el juez debe "inaplicar" las normas nacionales en pos de los criterios internacionales ${ }^{29}$ (para algún autor sólo se exceptuaría la Constitución ${ }^{30}$ ), pero a diferencia de lo señalado por los partidarios de la letra a), "sin que ello signifique anular, derogar o expulsar la norma jurídica interna del ordenamiento jurídico, ya que eventualmente podría tener efectos jurídicos en hipótesis de aplicación distintas que no

23 Ferrer Mac-Gregor (2011a), p. 389; Ferrer Mac-Gregor (2016a), pp. 15-16. Por negación, en caso que el juez no actúe: Nogueira (2013b), p. 244; Nogueira (2013a), p. 528.

24 Ferrer Mac-Gregor (2011a), pp. 371-372, énfasis añadido.

25 Binder (2010), p. 172; Jiménez García (2010), p. 100; Mejía (2014), p. 119; Ferrer Mac-Gregor (2011a), p. 389.

26 García Sayán (2009), pp. 101-102; Nogueira (2012a), p. 155; IbáÑez Rivas (2017), pp. 116-117.

27 Nogueira (2012c), p. 87.

28 Ferrer Mac-Gregor (2014), p. 239; Ferrer Mac-Gregor (2016b), p. 343; García Pino (2014), pp. 343

y 356; Nogueira (2012b), p. 1187; Ferrer Mac-Gregor (2011a), p. 395.

29 Castro et al (2017), p. 45; Pérez Manrique (2016), p. 411; SAgÜÉs (s/f b), pp. 384-385; Aguilar (2016a) pp. 136; Nogueira y Aguilar (2016), pp. 18-19.

30 García Belaúnde (2015), p. 130. 
entraran en conflicto con los derechos asegurados convencionalmente" ${ }^{11}$. Ello, a menos que este juez sí tenga "competencia anulatoria o derogatoria de normas contrarias a la Constitución" ${ }^{22}$, con lo cual podría eventualmente expulsar la disposición inonvencional. Por el contrario, si no posee esta facultad, debería elevar los antecedentes ante el tribunal nacional que sí la tenga ${ }^{33}$. Finalmente, en los casos en que el juez local sólo pueda inaplicar la norma cuestionada, esta situación debiera durar mientras esta disposición no sea modificada por las autoridades correspondientes ${ }^{34}$.

Lo anterior es importante, porque para la Corte no basta sólo con que se "inapliquen" las normas impugnadas: ellas deben ser suprimidas, a fin que no vuelvan a representar un peligro para los derechos humanos involucrados, pues al seguir existiendo, por mucho que se las deje de invocar en este momento, ello podría cambiar en el futuro ${ }^{35}$.

Por eso, "mientras se mantenga una norma o práctica violatoria de la Convención o se omita crear o aplicar una conforme a la misma, el 'control de convencionalidad' [realizado por los jueces internos] debe representar una respuesta para evitar que un nuevo caso resulte sometido a conocimiento del sistema interamericano o que un Estado reincida en la comisión de un acto generador de responsabilidad internacional, una vez emitida una sentencia de la Corte Interamericana que lo involucre" ${ }^{36}$. De ahí que "la no derogación de una norma incompatible con ésta y la falta de adaptación de las normas y comportamientos internos por parte de los poderes Legislativo y Judicial para hacer efectivas dichas normas, determinan que el Estado viole dicho tratado" ${ }^{37}$.

Ello y según se ha dicho, a menos que de acuerdo con la doctrina del control de convencionalidad desarrollada por la Corte, el juez cuente "con competencia anulatoria o derogatoria de normas contrarias a la Constitución” ${ }^{38}$, con lo cual

\footnotetext{
31 Nogueira (2012b), p. 1186, énfasis añadido. Ideas similares en García Pino (2014), p. 372; SagüÉs (2009a), p. 3; SAGÜÉs (2010), p. 128; NogUeIra (2013b), p. 265.

32 Nogueira (2012b), p. 1187; García Ramírez (2016), pp. 181-182; García Ramírez (2015), pp. 147-148. Lo plantea como pregunta, si bien habla de derogar la norma inconvencional, SAGÜÉs (s/fa), 462, pp. 461-462. 33 Ferrer Mac-Gregor (2011a), pp. 388-39o.

34 Hitters (2009), p. 114.

35 Ferrer MaC-Gregor (2015), pp. 95-96; Ferrer MaC-Gregor (2010), p. 187; Ivanschitz (2013), p. 317. De manera más vaga o indirecta, Mejía (2014), pp. 124-125; Ferrer MAC-Gregor (2014), p. 239.

36 IвÁÑez Rivas (2017), p. 112, énfasis añadido. Ideas complementarias en p. 105.

37 IbáÑEz Rivas (2017), p. 45, énfasis añadido. Ideas similares en p. 105. En un sentido parecido, Mejía (2014), pp. 123-125; Ferrer MAC-Gregor (2013), p. 666.

38 Nogueira (2012b), p. 1187. En parte, Castilla (2016), p. 110. Véase nota 32.
} 
podría eventualmente expulsar la norma inconvencional. Sin embargo, incluso en este caso, lo que interesa recalcar es que a diferencia de lo que pareciera transmitir la doctrina de la letra $a$ ), se requiere de una actuación interna del Estado y por tanto, que la norma no es expulsada automáticamente por los dictámenes de la Corte Interamericana ${ }^{39}$.

Por iguales motivos, la promulgación de una ley contraria a los criterios de la Corte produce responsabilidad internacional ${ }^{40}$, e incluso para algunos, una reforma constitucional infractora de la Convención Americana de Derechos Humanos no es válida, y así debe ser reputada por los jueces domésticos, a más de la Corte Interamericana" ${ }^{41}$.

Lo importante a recalcar después de todo lo dicho hasta aquí, es que sea cual sea la actuación que la Corte ordene al Estado condenado, la norma inconvencional incompatible con sus criterios sigue existiendo mientras estos órganos no actúen.

Por tanto, se puede concluir que la Corte "no se ocupa de modificar en forma directa el derecho interno, ya que su misión consiste en 'controlar' si las normas locales acatan -o no- las convenciones internacionales; y por ende -repetimos-, no se convierte en una 'cuarta instancia' que deja sin efecto las leyes de los países" ${ }^{2}$. O también, "Esto quiere significar que desde esta vertiente la decisión interamericana no implica una abrogación automática del precepto local, pues es el país quien debe cumplir con el pronunciamiento regional"43.

Con todo, se ha criticado que la Corte pueda dar órdenes en este sentido ${ }^{44}$.

Lo importante, repetimos, es constatar que a pesar de la declaración de inconvencionalidad hecha por la Corte, la norma interna sigue existiendo, con lo cual,

39 Por eso resulta muy adecuada esta definición de control de convencionalidad: "Doctrina creada por la Corte IDH en virtud de la cual un juez o tribunal nacional, en el marco de sus competencias, tiene la obligación de interpretar las normas internas conforme a la CADH, la jurisprudencia de la Corte IDH y las normas de ius cogens del Derecho Internacional de los Derechos Humanos, así como de inaplicar o invalidar una norma interna, cuando ésta sea incompatible con las obligaciones de dicho tratado, jurisprudencia y normas perentorias de derecho internacional antes reseñadas." (GARCía Pino y Contreras VÁsquez (2014), pp. 217-218).

40 Ferrer Mac-Gregor (2016a), pp. 14 y 15; Ferrer Mac-Gregor y Pelayo (2017), p. 100.

41 SAGǗ́s (2009b), p. 157, énfasis añadido.

42 Hitters (2008), pp. 135-136, énfasis añadido.

43 Hitters (2009), p. 123, énfasis añadido.

44 Malarino (2011), pp. 50-51 y 6o-61. 
dicha inconvencionalidad también continúa vigente ${ }^{45}$. Por eso "el país debe inmediatamente 'adaptar' la legislación interna -incluyendo su propia Constitución [...]- bajo apercibimiento de incurrir en responsabilidad estatal" ${ }^{\prime}$.

O si se prefiere, si el Estado da origen a (o no deroga) leyes contrarias a los dictámenes de la Corte, o no dicta leyes conformes a ella, cae en responsabilidad internacional ${ }^{47}$, pudiendo surgir ésta tanto por acción como por omisión ${ }^{48}$. Por eso, "Suponiendo que los Estados hagan caso omiso a esta recomendación, estas sanciones correspondería imponerlas a la Corte, declarando incompatible la legislación que favorece la impunidad y que el Estado no derogó" ${ }^{49}$. Mas lo importante es que la norma interna sigue existiendo.

La misma idea se refuerza si se recuerda que este tribunal no tiene el poder de imponer sus decisiones. Por eso "en definitiva, como sucede con diversas cuestiones inherentes a la operatividad del derecho internacional, las posibilidades de éxito del 'control de convencionalidad' están cifradas en el grado de receptividad de tal modalidad fiscalizatoria en los derechos internos, la labor de los respectivos operadores jurídicos involucrados y la voluntad política de los Estados"50.

En consecuencia, parece forzoso concluir que el control de convencionalidad externo es sólo un mecanismo que usa la Corte para determinar si existe o no compatibilidad entre la normativa interna y la Convención Americana y su jurisprudencia ${ }^{51}$. Constatada dicha incompatibilidad, ordena al Estado actuar para que esa apreciación tenga efectos, actuación que puede involucrar a varios organismos y mecanismos internos.

Por eso es necesario reconocer que para que produzca consecuencias en la práctica, el control de convencionalidad externo es completamente dependiente del control de convencionalidad interno, y sin su actuación se quedará solamente en las buenas intenciones. De ahí que se haya dicho que existen dos tipos de

45 IbÁÑez Rivas (2017), p. 105; Hitters (2009), pp. 118 y 125; Mejía (2014), p. 124; Londoño (2010), p. 804; Ferrer MaC-Gregor (2013), p. 666.

46 Hitters (2009), p. 125. Ideas similares en Ibáñez Rivas (2017), pp. 104-105.

47 Rey Cantor (2008), pp. 226-227.

48 Nogueira (2013b), pp. 264-265.

49 Rey CANTor (2008), p. 238, énfasis añadido.

50 BAzÁn (2017), p. 22, énfasis añadido. Ideas similares en p. 24. Reflexiones parecidas en Burgorgue-Larsen (2014), pp. 426-427, 431 y 435; Dulitzky (2015), p. 68; Mejía (2014), p. 120; Ivanschitz (2013), pp. 309-311.

51 Nogueira (2012b), p. 1168; Rey Cantor y Rey Amaya (2014), p. 240. 
control de normas internas: "la determinación directa de la nulidad de una ley a través de la Corte y la exigencia de no aplicación por los jueces nacionales"52.

Así entonces, lo que en el fondo ocurre con una declaración de inconvencionalidad, es que la Corte eventualmente puede ordenar al estado "crear" ${ }_{53}$-esto es, dictar o emitir-, "derogar, suprimir o modificar las normas o prácticas inconvencionales" 54 . Sobre este punto se manifiestan en el mismo sentido varios autores ${ }^{55}$, tarea que igualmente abarca al poder ejecutivo ${ }^{56}$, lo que conlleva en el fondo, organizar todo el aparato gubernamental57. Pero mientas ello no ocurra y según se ha dicho, la referida declaración de inconvencionalidad se dirige primeramente a los jueces, obligándolos a inaplicar la norma discordante, pues esa norma no es anulada, expulsada ni derogada del ordenamiento jurídico ${ }^{58}$.

En síntesis, y como muy bien ha dicho a este respecto Castilla:

"Es un gran error pretender meter en un mismo molde o entendimiento a operaciones jurídicas con naturaleza tan diferente (control de constitucionalidad/control de convencionalidad), por el simple hecho de que un tribunal u órgano internacional nunca expulsa, ni inaplica como principal resultado del ejercicio de su competencia a las normas que se opongan al tratado, sino tan solo determinará el incumplimiento de una obligación internacional y, posterior a ello, indirectamente podría pedir que se inaplique o expulse una norma, pero dejando eso a cargo del Estado internacionalmente responsable, y sin que en todos los casos eso sea la regla a seguir. Como también porque un órgano nacional nunca va a poder determinar la responsabilidad internacional, si más bien, puede ser la fuente de ello" ${ }^{9}$.

Por iguales razones, se ha comentado que "En el pasado, la Corte no se arrogó el poder de invalidar normas domésticas" ${ }^{60}$ : antes, solo decía que una norma contraria a la Convención generaba responsabilidad internacional ${ }^{61}$. Por tanto, no

52 Binder (2010), p. 169.

53 SagüÉs (2015a), p. 146; Castilla (2016), p. 120; Escobar Fornos (2014), p. 1109; Ferrer Mac-Gregor (2016b), p. 343; SAGÜÉs (2014), pp. 26-27.

54 García Pino (2014), p. 357; Nogueira (2012b), p. 1186; Nogueira (2013b), pp. 265 y 267; Nogueira (2013a), pp. 546-548; NogUeIRA (2012c), p. 75.

55 Bazán (2017), p. 16; Paúl (2013), pp. 337-338; Becerra Ramírez (2013), p. 89; Carvajal y Guzmán (2017), p. 199; PiOvesan (2014), p. 65.

56 IbÁÑez Rivas (2017), pp. 93-94: SAGÜÉs (2015a), pp. 146-147.

57 García Ramírez (2011), p. 146.

58 Vid nota 39.

59 Castilla (2013), p. 74, énfasis añadido. Ideas en parte similares en SAGÜÉs (2009a), p. 6.

6o Dulitzky (2015), p. 67.

61 Dulitzky (2015), p. 67. 
seguir los mandatos de la Corte a lo sumo generaría una nueva responsabilidad internacional, y así sucesivamente ${ }^{62}$, como puede apreciarse en varias supervisiones de cumplimiento, tema que en parte será abordado en el epígrafe siguiente.

Estas son, pues, las dos posturas que existen respecto de los efectos que produce la declaración de inconvencionalidad realizada por la Corte Interamericana: la "fuerte" y la "débil", todo lo cual refuerza nuestra impresión que se trata de un punto poco claro. Lo anterior también se refleja en la nomenclatura extraordinariamente heterogénea que utiliza la doctrina a su respecto, sea que se encuentre en una u otra posición. Para intentar dar más luz sobre este asunto, se procederá a analizar la jurisprudencia que a este respecto ha dictado la propia Corte hasta finales del año 2018, tanto antes como después del surgimiento de la teoría del control de convencionalidad.

\section{Análisis jurisprudencial}

En realidad, los propios pasajes en que la Corte formula la obligación de llevar a cabo el control de convencionalidad interno muestran, sea antes o después de ordenarlo, que las normas incompatibles con su jurisprudencia siguen existiendo. Ello, pese a que señala expresamente que las normas inconvencionales que no dan posibilidad a una armonización con los criterios internacionales, "carecen de efectos jurídicos" ${ }^{63}$, incluso "desde un inicio" ${ }^{64}$.

Debe recordarse que la Corte ha establecido la obligación de realizar una interpretación conforme en prácticamente todos los fallos que llaman a hacer el control de convencionalidad ${ }^{65}$. Sin embargo, y tal como se ha señalado anteriormente,

62 VIO (2015), pp. 99-103.

63 Herzog y otros vs. Brasil (2018), párr. 292; Zegarra Marín vs. Perú. S.C. (2018), párr. 1; Rochac Hernández y otros vs. El Salvador (2014), párr. 213; Gelman vs. Uruguay (2011), párr. 253 y punto resolutivo 11; Gomes Lund y otros ("Guerrilha do Araguaia") vs. Brasil. S.C. (2014), párr. 18.

64 Almonacid Arellano y otros vs. Chile (2006), párr. 124; La Cantuta vs. Perú (2006), párr. 173; Gomes Lund y otros ("Guerrilha do Araguaia") vs. Brasil. S.C. (2014), párr. 16; Radilla Pacheco vs. México (2009), párr. 339; Ibsen Cárdenas e Ibsen Peña vs. Bolivia (2010), párr. 202.

65 Andrade Salmón vs. Bolivia (2016), párr. 93; Pollo Rivera y otros vs. Perú (2016), párr. 224; López Lone $y$ otros vs. Honduras (2015), párr. 307; Comunidad Garífuna de Punta Piedra y sus Miembros vs. Honduras (2015), párr. 211, 255 y 346; Cabrera García y Montiel Flores vs. México. S.C. (2015), párr. 21; Personas dominicanas y haitianas expulsadas vs. República Dominicana (2014), párr. 453; Hermanos Landaeta Mejías y otros vs. Venezuela (2014), párr. 158; Supervisión Conjunta de 11 Casos vs. Guatemala. S.C. (2014), párr. 17; Castillo Petruzzi y otros vs. Perú. S.C. (2011), párr. 20; Furlan y Familiares vs. Argentina (2012), párr. 304; Lori Berenson Mejía vs. Perú. S.C. (2012), párr. 18; Atala Riffo y Niñas vs. Chile (2012), párr. 284; Chocrón Chocrón vs. 
este tema no es analizado en este trabajo, sino sólo aquellos casos en que la norma objetada resulta incompatible con sus criterios.

De esta manera, en un principio dirá respecto de las autoridades internas, que la aplicación del control de convencionalidad "les obliga a velar porque los efectos de las disposiciones de la Convención no se vean mermados por la aplicación de leyes contrarias a su objeto y fin" ${ }^{\prime 6}$, si bien en alguna oportunidad cambiará levemente la parte final de la frase, señalando que dicho efecto "no quede mermado o anulado por la aplicación de normas o prácticas internas contrarias al objeto y fin del instrumento internacional" ${ }^{67}$. Con todo, la frase más común expresada a lo largo del tiempo señala que "no se vean mermados por la aplicación de normas contrarias a su objeto y fin" ${ }^{\prime \prime}$, siendo también usual esta última frase en varias supervisiones de cumplimiento ${ }^{69}$, con variantes como que "se vean mermados por la aplicación de leyes contrarias a sus disposiciones, objeto y fin" ${ }^{\circ}$, o finalmente, "por la aplicación de normas o interpretaciones contrarias a su objeto y fin"71. Por último, a veces sólo menciona que estas obligaciones son "mermadas", sin especificar cómo $^{72}$. Ahora bien, lo importante para efectos del presente estudio es que todas

Venezuela (2011), párr. 172; Rosendo Cantú y otra vs. México (2010), párr. 220; Fernández Ortega y otros vs. México (2010), párr. 237.

66 Almonacid Arellano y otros vs. Chile (2006), párr. 124, énfasis añadido. Con iguales palabras, en Raxcacó Reyes vs. Guatemala. S.C. (09.05.2008), párr. 63; Comunidad Indígena Xákmok Kásek vs. Paraguay (2010), párr. 311; Radilla Pacheco vs. México (2009), párr. 339; "Cinco Pensionistas" vs. Perú. S.C. (2009), párr. 35.

67 Heliodoro Portugal vs. Panamá (2008), párr. 180, énfasis añadido.

68 Chinchilla Sandoval vs. Guatemala (2016), párr. 242; García Ibarra y otros vs. Ecuador (2015), párr. 103, nota 125; López Lone y otros vs. Honduras (2015), párr. 307; Personas dominicanas y haitianas expulsadas vs. República Dominicana (2014), párr. 311; García Cruz y Sánchez Silvestre vs. México (2013), párr. 59, nota 76; Furlan y Familiares vs. Argentina (2012), párr. 302; López Mendoza vs. Venezuela (2011), párr. 226; Cabrera García y Montiel Flores vs. México (2010), párr. 225; Fernández Ortega y otros vs. México (2010), párr. 236; Boyce y otros vs. Barbados (2007), párr. 113.

69 López Mendoza vs. Venezuela. S.C. (2015), párr. 10; Gomes Lund y otros ("Guerrilha do Araguaia”) vs. Brasil. S.C. (2014), párr. 16; Anzualdo Castro vs. Perú. S.C. (2013), párr. 24; Masacres de Ituango vs. Colombia. S.C. (2013), párr. 29; Apitz Barbera y Otros ("Corte Primera de lo Contencioso Administrativo") vs. Venezuela. S.C. (2012), párr. 26.

70 Trabajadores Cesados del Congreso (Aguado Alfaro y Otros) vs. Perú. Solicitud de Interpretación (2007), párr. 128; Vélez Loor vs. Panamá (2010), párr. 287.

71 Miembros de la Aldea Chichupac y comunidades vecinas del Municipio de Rabinal vs. Guatemala (2016), párr. 289; Masacre de Santo Domingo vs. Colombia (2012), párr. 142, nota 193; Gudiel Álvarez y otros (Diario Militar) vs. Guatemala (2012), párr. 330; Masacres de Río Negro vs. Guatemala (2012), párr. 262; Fontevecchia y D 'Amico vs. Argentina (2011), párr. 93.

72 Loayza Tamayo vs. Perú. S.C. (2011), párr. 40; Ivcher Bronstein vs. Perú. S.C. (2010), párr. 13; Ivcher Bronstein vs. Perú. S.C. (2009), párr. 17; Bulacio vs. Argentina. S.C. (2008), párr. 18. 
estas aseveraciones serían innecesarias si la norma inconvencional no continuara vigente.

Por lo mismo y de manera opuesta, la existencia de la norma inconvencional es reconocida cuando señala que "El cumplimiento por parte de agentes ofuncionarios del Estado de una ley violatoria de la Convención produce responsabilidad internacional del Estado"73. O si se prefiere, "dado que la Ley de Amnistía General para la Consolidación de la Paz carece de efectos [...], el Estado debe asegurar que aquélla no vuelva a representar un obstáculo para la investigación de los hechos materia del presente caso [...]. Esta obligación vincula a todos los poderes y órganos estatales en su conjunto, los cuales se encuentran obligados a ejercer un control 'de convencionalidad'..."74.

Todo lo antes dicho demuestra, por tanto, que la norma inconvencional incompatible sigue existiendo, pese a lo señalado por la Corte en cuanto a que "carezca de efectos jurídicos", incluso "desde un inicio", pues en estricto rigor, las autoridades internas pueden seguir aplicándola, sin perjuicio de la responsabilidad internacional que ello conlleve.

Lo cual está en perfecta armonía con lo que la Corte ha expresado de manera muy clara y permanente: "un Estado que ha celebrado un convenio internacional, debe introducir en su derecho interno las modificaciones necesarias para asegurar la ejecución de las obligaciones asumidas"75. Ello ha sido afirmado tanto antes del caso Almonacid ${ }^{76}$, como luego del mismo, de manera insistente y constante a lo largo de los años ${ }^{77}$. Para la Corte, "Este deber general del Estado Parte implica

73 Almonacid Arellano y otros vs. Chile (2006), párr. 123, énfasis añadido. La misma idea en La Cantuta vs. Perú (2006), párr. 173; Cabrera García y Montiel Flores vs. México (2010), párr. 123; Raxcacó Reyes vs. Guatemala y Fermín Ramírez vs. Guatemala. S.C. (09.05.2008), párr. 63.

74 Herzog y otros vs. Brasil (2018), párr. 138, 251, 281 y 292; Trabajadores de la Hacienda Brasil Verde vs. Brasil (2016), párr. 413; Tenorio Roca y otros vs. Perú (2016), párr. 217; García Lucero y otras vs. Chile. S.C. (2015), párr. 150, 154, 223 y punto resolutivo 4; Gelman vs. Uruguay (2011), párr. 253-254 y punto dispositivo 11; Gomes Lund y otros ("Guerrilha do Araguaia") vs. Brasil (2010), párr. 174 y punto declarativo 3; Almonacid Arellano y otros vs. Chile (2006), párr. 145 y 119, puntos dispositivos 5 y 6; La Cantuta vs. Perú (2006), párr. 175; Barrios Altos vs. Perú. Interpretación de la Sentencia (2001), párr. 15; Barrios Altos vs. Perú. Fondo (2001), párr. 44. 75 Almonacid Arellano y otros vs. Chile (2006), párr. 117, énfasis añadido.

76 Garrido y Baigorria vs. Argentina (1998), párr. 68; Durand y Ugarte vs. Perú (200o), párr. 136; “Cinco Pensionistas" vs. Perú (2003), párr. 164; Bulacio vs. Argentina (2003), párr. 140-142; "Instituto de Reeducación del Menor" vs. Paraguay (2004), párr. 205-206.

77 La Cantuta vs. Perú (2006), párr. 170-171; Zambrano Vélez y otros vs. Ecuador (2007), párr. 55; Castañeda Gutman vs. México (2008), párr. 132; Radilla Pacheco vs. México (2009), párr. 288; Barreto Leiva vs. Venezuela (2009), párr. 106; Ibsen Cárdenas e Ibsen Peña vs. Bolivia (2010), párr. 193; Torres Millacura y otros vs. Argentina (2011), párr. 148; Forneron e hija vs. Argentina (2012), párr. 130; Osorio Rivera y Familiares vs. Perú(2013), 
que las medidas de derecho interno han de ser efectivas (principio del effet utile), para lo cual el Estado debe adaptar su actuación a la normativa de protección de la Convención" $n^{78}$, siendo consciente que lo anterior requiere de un "plazo razonable"79, aunque no demasiado ${ }^{80}$. En esta tarea debe ejercerse "un control de convencionalidad tanto en la emisión y aplicación de normas, en cuanto a su validez y compatibilidad con la Convención"\$1.

Y al contrario, la no modificación de las normas internas -tarea que sólo corresponde a las autoridades domésticas- "despoja el efecto útil de la Convención" 82 .

Ahora bien, en cuanto a las clases de reforma que el Estado debe introducir, la Corte también ha sido meridiana y profusamente clara: "A la luz del artículo 2 de la Convención, tal adecuación implica la adopción de medidas en dos vertientes, a saber: i) la supresión de las normas y prácticas de cualquier naturaleza que entrañen violación a las garantías previstas en la Convención, y ii) la expedición de normas y el desarrollo de prácticas conducentes a la efectiva observancia de dichas garantías" ${ }^{3}$.

Es decir, "los Estados no sólo tienen la obligación positiva de adoptar las medidas legislativas necesarias para garantizar el ejercicio de los derechos en ella consagrados, sino que también deben evitar promulgar aquellas leyes que impidan el libre ejercicio de estos derechos, y evitar que se supriman o modifiquen las leyes que

párr. 204; Osorio Rivera y familiares vs. Perú. Interpretación de la Sentencia (2014), párr. 19; Omar Humberto Maldonado Vargas y otros vs. Chile (2015), párr. 104 y 124; Maldonado Ordoñez vs. Guatemala (2016), párr. 111; Trabajadores de la Hacienda Brasil Verde vs. Brasil (2016), párr. 409 y 429; Ticona Estrada y otros vs. Bolivia. Interpretación de la Sentencia (2009), párr. 101; Gelman vs. Uruguay. S.C. (2013), párr. 37 y 60, nota 42.

78 Gómez Palomino vs. Perú (2005), párr. 91, énfasis añadido. La misma idea en Lori Berenson Mejía vs. Perú (2004), párr. 220; Yatama vs. Nicaragua (2005), párr. 170.

79 Chaparro Álvarez y Lapo Íñiguez. vs. Ecuador (2007), párr. 268; López Mendoza vs. Venezuela (2011), párr. 225; Mendoza y otros vs. Argentina (2013), párr. 232.

80 Barreto Leiva vs. Venezuela (2009), párr. 108; Heliodoro Portugal vs. Panamá (2008), párr. 187.

81 Supervisión conjunta de 11 Casos vs. Guatemala. S.C. (2014), párr. 17. Ideas similares en Gelman vs. Uruguay. S.C. (2013), párr. 69; Masacres de Río Negro y Gudiel Álvarez y otros vs. Guatemala. S.C. (2014), párr. 17.

82 Penal Miguel Castro Castro vs. Perú. S.C. (2017), párr. 37; Penal Miguel Castro Castro vs. Perú. S.C. (2015), párr. 21; Hilaire, Constantine y Benjamin y otros y Caesar vs. Trinidad y Tobago. S.C. (2015), párr. 11; Ríos y otros, Perozo y otros y Reverón Trujillo vs. Venezuela. S.C. (2015), párr. 11; Yatama vs. Nicaragua. S.C. (2015), párr. 2 y 11; Yatama vs. Nicaragua. S.C. (2013), párr. 15; El Amparo, Blanco Romero y otros, Montero Aranguren y otros, Barreto Leiva y Usón Ramírez vs. Venezuela. S.C. (2015), párr. 12.

83 Almonacid Arellano y otros vs. Chile (2006), párr. 118, énfasis añadido. También lo señala en J. vs. Perú. Interpretación de la Sentencia (2014), párr. 407; Barreto Leiva vs. Venezuela (2009), párr. 107; Ramírez Escobar y otros vs. Guatemala (2018), párr. 243; Amrhein y otros vs. Costa Rica (2018), párr. 259. 
los protegen" ${ }^{4}$. O si se prefiere, "implica el deber de los Estados Partes de organizar todo el aparato gubernamental y, en general, todas las estructuras a través de las cuales se manifiesta el ejercicio del poder público, de manera tal que sean capaces de asegurar jurídicamente el libre y pleno ejercicio de los derechos humanos"85.

Con todo, la Corte ha señalado que aun cuando sea muy importante la labor normativa, "También se requiere el desarrollo de prácticas estatales conducentes a la observancia efectiva de los derechos y libertades consagrados en la misma. En consecuencia, la existencia de una norma no garantiza por sí misma que su aplicación sea adecuada. Es necesario que la aplicación de las normas o su interpretación, en tanto prácticas jurisdiccionales y manifestación del orden jurídico, se encuentren ajustadas al mismo fin que persigue el artículo 2 de la Convención"86.

No obstante, "el artículo 2 de la Convención no define cuáles son las medidas pertinentes para la adecuación del derecho interno a la misma, obviamente por depender ello del carácter de la norma que la requiera y las circunstancias de la situación concreta" ${ }^{87}$.

Por su parte, la "supresión" debe comprender "las normas y prácticas de cualquier naturaleza que entrañen violación a las garantías previstas en la Convención o que desconozcan los derechos allí reconocidos u obstaculicen su ejercicio" Debido a lo anterior, dicha obligación se incumple "mientras la norma o práctica

84 Mendoza y otros vs. Argentina (2013), párr. 323, énfasis añadido. La misma idea en Boyce y otros vs. Barbados (2007), párr. 69; Dacosta Cadogan vs. Barbados (2009), párr. 68; Atala Riffo y Niñas vs. Chile (2012), párr. 279; Tribunal Constitucional (Camba Campos y otros) vs. Ecuador (2013), párr. 275; Trabajadores Cesados de Petroperú y otros vs. Perú (2017), párr. 186; Barrios Altos vs. Perú. Interpretación de la Sentencia (2001), párr. 18.

85 Velásquez Rodríguez vs. Honduras (1988), párr. 166, énfasis añadido. Ideas similares en párr. 158. La misma idea en Anzualdo Castro vs. Perú (2009), párr. 62; Pueblo Indígena Xucuru y sus miembros vs. Brasil (2018), párr. 121; Miembros de la Aldea Chichupac y comunidades vecinas del Municipio de Rabinal vs. Guatemala (2016), párr. 288; Bueno Alves vs. Argentina. S.C. (2011), párr. 33; Heliodoro Portugal vs. Panamá. S.C. (2017), párr. 9; Bámaca Velásquez vs. Guatemala. S.C. (2009), párr. 24; Montero Aranguren y Otros (Retén de Catia) vs. Venezuela. (2011), párr. 16; Ivcher Bronstein vs. Perú. (2009), párr. 12; Bámaca Velásquez vs. Guatemala. (2010), párr. 27.

86 J. vs. Perú. Interpretación de la Sentencia (2014), párr. 407, énfasis añadido. La misma idea en Ramírez Escobar y otros vs. Guatemala (2018), párr. 243; Lori Berenson Mejía vs. Perú. (2012), párr. 18; Loayza Tamayo vs. Perú. (2011), párr. 35; Castillo Petruzzi y otros vs. Perú. (2011), párr. 20.

87 La Cantuta vs. Perú (2006), párr. 172; Zambrano Vélez y otros vs. Ecuador (2007), párr. 57.

88 Maldonado Ordoñez vs. Guatemala (2016), párr. 111; Forneron e hija vs. Argentina (2012), párr. 131; Ramírez Escobar y otros vs. Guatemala (2018), párr. 243; Amrhein y otros vs. Costa Rica (2018), párr. 259; Gómez Palomino vs. Perú (2005), párr. 91. 
violatoria de la Convención se mantenga en el ordenamiento jurídico" 89 . E insiste: la obligación de adecuar el orden interno "sólo se satisface cuando efectivamente se realiza la reforma"90.

Desde una perspectiva complementaria, la Corte vuelve a reconocer la existencia de las normas declaradas inconvencionales, en razón a que la obligación de expedir normas y prácticas, "obliga al Estado a prevenir la recurrencia de violaciones a los derechos humanos y, por eso, debe adoptar todas las medidas legales, administrativas y de otra índole que sean necesarias para evitar que hechos similares vuelvan a ocurrir en el futuro" 91 . Ello, pues "las medidas de derecho interno han de ser efectivas (principio de effet utile)"92.

Finalmente -muy importante para este estudio-, en cuanto a la "supresión" de las normas consideradas inconvencionales, este tribunal ha señalado también de forma constante que "la norma o práctica violatoria de la Convención debe ser modificada, derogada, o anulada, o reformada, según corresponda"93.

Debido a análogas razones, en múltiples ocasiones la Corte ha ordenado tipificar ciertos delitos ${ }^{94}$. Y al contrario, si la normativa interna ya coincide con lo dispuesto por la Convención, no ha mandado realizar modificación alguna ${ }^{95}$. E

89 La Cantuta vs. Perú (2006), párr. 172, énfasis añadido. La misma idea en Vélez Loor vs. Panamá (2010), párr. 194.

90 Almonacid Arellano y otros vs. Chile (2006), párr. 118, énfasis añadido. La misma idea en Raxcacó Reyes vs. Guatemala (2005), párr. 87; Palamara Iribarne vs. Chile (2005), párr. 89. En otros casos, la Corte habla de una obligación "de resultado": Caesar vs. Trinidad y Tobago (2005), párr. 91 y 93; Comunidad Indígena Yakye Axa vs. Paraguay (2005), párr. 100.

91 Forneron e hija vs. Argentina (2012), párr. 131, énfasis añadido; Granier y otros (Radio Caracas Televisión) vs. Venezuela (2015), párr. 389; Familia Pacheco Tineo vs. Bolivia (2013), párr. 265 y 269; Montero Aranguren y Otros (Retén de Catia) vs. Venezuela (2006), párr. 143; Salvador Chiriboga vs. Ecuador (2008), párr. 122.

92 Trabajadores de la Hacienda Brasil Verde vs. Brasil (2016), párr. 409; Nadege Dorzema y otros vs. República Dominicana (2012), párr. 216; Zambrano Vélez y otros vs. Ecuador (2007), párr. 56; Fermín Ramírez vs. Guatemala (2005), párr. 55-56; Omar Humberto Maldonado Vargas y otros vs. Chile (2015), párr. 124.

93 Maldonado Ordoñez vs. Guatemala (2016), párr. 111; Omar Humberto Maldonado Vargas y otros vs. Chile (2015), párr. 124; Zambrano Vélez y otros vs. Ecuador (2007), párr. 57; La Cantuta vs. Perú (2006), párr. 172; Forneron e hija vs. Argentina (2012), párr. 131; Trabajadores de la Hacienda Brasil Verde vs. Brasil (2016), párr. 410; Vélez Loor vs. Panamá (2010), párr. 194.

94 Osorio Rivera y Familiares vs. Perú (2013), párr. 204-212, 221, 271 y punto dispositivo 12; Vélez Loor vs. Panamá (2010), párr. 289-292; Heliodoro Portugal vs. Panamá (2008), párr. 181-200, 209, 214, 215, 216, 257-259 y puntos resolutivos 7, 8 y 16; Hermanas Serrano Cruz vs. El Salvador (2005), párr. 28 y 174; Baena Ricardo y otros vs. Panamá (2001), párr. 123.

95 Norín Catrimán y otros (Dirigentes, miembros y activista del pueblo indígena mapuche) vs. Chile (2014), párr. 461. 
incluso a veces, pese a que no se han realizado las reformas exigidas, no ha considerado necesario ordenarlas nuevamente ${ }^{96}$.

Por iguales razones, en varias oportunidades el Estado ha informado a la Corte que ha llevado a cabo las reformas ordenadas ${ }^{97}$. Y en más de una ocasión, tanto la Comisión Interamericana como los representantes de las víctimas, han reclamado por haberse incumplido esta obligación ${ }^{98}$. E incluso la misma Corte ha hecho otro tanto 99 .

Ahora bien, desde una perspectiva complementaria, otra valiosa pista para saber qué ocurre con las normas inconvencionales la otorgan las supervisiones de cumplimiento.

En efecto, al margen de si se ha ordenado o no realizar el control de convencionalidad en la sentencia definitiva (o a veces también en alguna supervisión de cumplimiento $\left.{ }^{100}\right)$, existen varias resoluciones de esta especie en las cuales la Corte critica que el Estado no haya introducido las reformas legales ordenadas por ella misma ${ }^{101}$, todo lo cual reafirma que la norma inconvencional sigue existiendo.

96 Masacres de El Mozote y lugares aledaños vs. El Salvador. S.C. (2017), párr. 7; Vélez Loor vs. Panamá (2010), párr. 291-292; Heliodoro Portugal vs. Panamá (2008), párr. 259; Rochac Hernández y otros vs. El Salvador (2014), párr. 213; Masacres de El Mozote y lugares aledaños vs. El Salvador (2012), párr. 357.

97 Masacres de El Mozote y lugares aledaños vs. El Salvador. S.C. (2017), párr. 18 y punto resolutivo 1; Cabrera García y Montiel Flores vs. México. S.C. (2015), párr. 6 y 16; Radilla Pacheco, Fernández Ortega y otros, y Rosendo Cantú y otra vs. México. S.C. (2015), párr. 6.

98 Órdenes Guerra y otros vs. Chile (2018), párr. 88 y 96; Zegarra Marín vs. Perú (2017), párr. 164; Flor Freire vs. Ecuador (2016), párr. 196; Tenorio Roca y otros vs. Perú (2016), párr. 220; Castañeda Gutman vs. México. S.C. (2013), párr. 14; Nadege Dorzema y otros vs. República Dominicana (2012), párr. 204; Raxcacó Reyes vs. Guatemala. S.C. (28.03.2008), párr. 67 y 68.

99 Anzualdo Castro vs. Perú. S.C. (2013), párr. 23; Apitz Barbera y Otros ("Corte Primera de lo Contencioso Administrativo") vs. Venezuela. S.C. (2012), párr. 26. De manera algo distinta ("el Estado debió haber adoptado"), Masacres de Ituango vs. Colombia. S.C. (2013), párr. 27.

100 SiLVA (2018), pp. 725 y $738-744$.

101 Se trata de una situación muy común, como puede verse por ejemplo en: Pueblo Saramaka vs. Surinam. S.C. (2018), punto resolutivo 2c); Norín Catrimán y otros (Dirigentes, Miembros y Activista del Pueblo Indígena Mapuche) vs. Chile. S.C. (2018), punto resolutivo 3d); Comunidad Moiwana vs. Surinam. S.C. (2018), punto resolutivo 1c); Pacheco Teruel y otros vs. Honduras. S.C. (2017), punto resolutivo 2b) y 2d); Velásquez Paiz y otros vs. Guatemala. S.C. (2017), punto resolutivo 2h); Palamara Iribarne vs. Chile. S.C. (2016), punto resolutivo 1a) y 1b); Chaparro Álvarez y Lapo Íñiguez vs. Ecuador. S.C. (2016), punto resolutivo 2; Yvon Neptune vs. Haití. S.C. (2015), punto resolutivo 2b) y 2d); Hilaire, Constantine y Benjamin y otros y Caesar vs. Trinidad y Tobago. S.C. (2015), punto resolutivo: 2 a) y 2b) [casos Hilaire y Constantine] y 2c), 2d) y 2e) [caso Caesar]; Chaparro Álvarez y Lapo Íñiguez vs. Ecuador. S.C. (2015), punto resolutivo 2a); Radilla Pacheco vs. México. S.C. (2013), punto resolutivo 2c) y 2d); Barrios Altos vs. Perú. S.C. (2012), punto declarativo 2g); Masacre de las Dos Erres vs. Guatemala. S.C. (2012), punto declarativo 2c); Pueblo Saramaka vs. Surinam. S.C. (2011), punto declarativo 3b), 3c), 3d) y 3f); Blanco Romero y otros vs. Venezuela. S.C. (2011), punto declarativo 3d) y 3e); Boyce y otros vs. Barbados. S.C. (2011), punto declarativo 1a), 1b), 1c), 6a) y 6b); Niñas Yean y Bosico vs. Repú- 
Y por el contrario, este tribunal ha reconocido en múltiples oportunidades que las modificaciones legales ordenadas se llevaron a cabo, al menos de manera parcial, cumpliendo así con el fallo ${ }^{102}$, con lo cual se vuelve a confirmar que es necesaria esa actuación del Estado para que la sentencia tenga efectos dentro del país condenado.

En otros casos, la Corte ha solicitado informes al Estado condenado a fin de poder determinar si las reformas ordenadas han sido realizadas ${ }^{103}$, todo lo cual indica que es altamente probable que las leyes cuestionadas -inconvencionalessigan vigentes.

Finalmente, en diversas ocasiones, este tribunal ha reprochado al Estado haber realizado una interpretación inadecuada de sus leyes internas ${ }^{104}$; que la no modificación de las leyes es un obstáculo para el cumplimiento de la sentencia (o lo contrario: que su modificación ha removido dicho obstáculo) ${ }^{105}$; o finalmente, ha

blica Dominicana. S.C. (2011), punto declarativo 3b); Gómez Palomino vs. Perú. S.C. (2011), punto declarativo 3a); Palamara Iribarne vs. Chile. S.C. (2011), punto declarativo 1b); Radilla Pacheco vs. México. S.C. (2011), punto declarativo 2c) y 2d); Chaparro Álvarez y Lapo Íñiguez vs. Ecuador. S.C. (2011), punto declarativo 3b); Niñas Yean y Bosico vs. República Dominicana. S.C. (2010), punto declarativo 2b); Yatama vs. Nicaragua. S.C. (28.05.2010), punto declarativo 2b), 2c) y 2d); Chaparro Álvarez y Lapo Íñiguez vs. Ecuador. S.C. (2010), punto declarativo 3b); Montero Aranguren y otros (Retén de Catia) vs. Venezuela. S.C. (2009), punto declarativo 1c) d); Molina Theissen vs. Guatemala. S.C. (2009), punto declarativo 2d); Blanco Romero y otros vs. Venezuela. S.C. (2009), punto declarativo 2d) y 2e); Chaparro Álvarez y Lapo Íñiguez vs. Ecuador. S.C. (2009), punto declarativo 3c) y $3 \mathrm{~d}$ ).

102 Heliodoro Portugal vs. Panamá. S.C. (2017), punto resolutivo 1; Maldonado Ordóñez vs. Guatemala. S.C. (2017), punto resolutivo 1e); Goiburú y otros vs. Paraguay. S.C. (2017), punto resolutivo 1; Heliodoro Portugal vs. Panamá. S.C. (2012), puntos resolutivos 1 y 2 (aunque en el punto 3 señala los cambios que no se han realizado); Loayza Tamayo vs. Perú. S.C. (2011), puntos declarativos 1b) y 1c); Castillo Petruzzi y otros vs. Perú. S.C. (2011), punto declarativo 1b); Kimel vs. Argentina. S.C. (2010), punto declarativo 1d); Zambrano Vélez y otros vs. Ecuador. S.C. (2009), punto declarativo 1c); Bámaca Velásquez vs. Guatemala. S.C. (2009), punto declarativo 1; Bulacio vs. Argentina. S.C. (2008), punto declarativo 1b).

103 Bueno Alves vs. Argentina. S.C. (2018), Puntos resolutivos 2 y 3; Chocrón Chocrón, Díaz Peña, y Uzcátegui y otros vs. Venezuela. S.C. (2016), punto resolutivo 4; Comunidades Indígenas Yakye Axa, Sawhoyamaxa y Xákmok Kásek vs. Paraguay. S.C. (2016), punto resolutivo 1 (en relación a párr. 13.5, 13.6 y 19); Chocrón Chocrón, Díaz Peña, y Uzcátegui y otros vs. Venezuela. S.C. (2015), punto resolutivo 5; Yatama vs. Nicaragua. S.C. (2011), punto resolutivo 2 (en relación con Vistos, párr. 2); Yatama vs. Nicaragua. S.C. (21.04.2010), punto resolutivo 1; Herrera Ulloa vs. Costa Rica. S.C. (2009), punto resolutivo 1; Niñas Yean y Bosico vs. República Dominicana. S.C. (2009), punto resolutivo 1; Bámaca Velásquez vs. Guatemala. S.C. (2008), punto resolutivo 1; Comunidad Indígena Sawhoyamaxa vs. Paraguay. S.C. (2007), punto resolutivo 4b); Bámaca Velásquez vs. Guatemala. S.C. (2003), punto resolutivo 4.

104 Gomes Lund y otros ("Guerrilha do Araguaia") vs. Brasil. S.C. (2014), Punto resolutivo 5.

105 Masacres de El Mozote y lugares aledaños vs. El Salvador. S.C. (2017), punto resolutivo 1; Comunidades Indígenas Yakye Axa, Sawhoyamaxa y Xákmok Kásek vs. Paraguay. S.C. (2017), punto resolutivo 3c) 11; García Lucero y otras vs. Chile. S.C. (2015), Punto resolutivo 2. 
denunciado la existencia de problemas estructurales que impiden el cumplimiento de lo dispuesto por el fallo ${ }^{106}$.

Por tanto, a la luz de todas las resoluciones citadas hasta aquí, se puede concluir que en cuanto a su existencia, la norma interna incompatible no se ve afectada de manera directa por el control de convencionalidad ejercido por la Corte Interamericana, sino que requiere de la actuación de las autoridades nacionales, a través del control de convencionalidad interno.

Ahora bien, siendo lo anterior evidente, la Corte ha dirigido la orden de realizar el control de convencionalidad primeramente a los jueces internos. Es por eso que ha dicho que cuando el legislador "falla" en su deber de protección de los derechos humanos, son los jueces nacionales quienes deben cumplir con esta labor $^{107}$. De ahí que considere que es un deber de estos jueces locales llevar a cabo el control de convencionalidad ${ }^{108}$.

En suma, lo que ocurre a fin de cuentas, es que al margen de las modificaciones legales necesarias vistas más arriba, la Corte ordena que la norma interna incompatible con sus propios criterios, y que sigue intacta, no sea aplicada -hasta que sea "modificada, derogada, o anulada, o reformada"109_ y que en su lugar, los jueces utilicen dichos criterios: "En conclusión, independientemente de las reformas legales que el Estado deba adoptar [...], es necesario que las interpretaciones judiciales referidas a las garantías judiciales y demás derechos de los jueces provisorios y temporales se realicen a la luz de la independencia judicial, adecuándose a los principios establecidos en la jurisprudencia de este Tribunal"110. O como dice en otro lugar, "El órgano judicial tiene la función de hacer prevalecer la Convención

10612 Casos Guatemaltecos vs. Guatemala. S.C. (2015), párr. 1, 36, 44, 89, 122-163, 173, 174, 175a, 175b) vii y 175b) xi; Kawas Fernández y Caso Luna López vs. Honduras. S.C. (2017), párr. 45 y 47; Hermanas Serrano Cruz vs. El Salvador. S.C. (2016), párr. 19 a) ii); Contreras y otros vs. El Salvador. S.C. (2016), párr. 36 a) ii).

107 Almonacid Arellano y otros vs. Chile (2006), párr. 123; La Cantuta vs. Perú (2006), párr. 173; Raxcacó Reyes vs. Guatemala. S.C. (09.05.2008), párr. 63. De manera menos fuerte, Chinchilla Sandoval vs. Guatemala (2016), párr. 243.

108 Masacres de Ituango vs. Colombia. S.C. (2013), párr. 30; Barrios Altos y La Cantuta vs. Perú. S.C. (2018), párr. 65.

109 Vid supra nota 93.

110 Chocrón Chocrón vs. Venezuela (2011), párr. 172, remitiéndose al párr. 162, énfasis añadido. Similares ideas en Raxcacó Reyes vs. Guatemala y Fermín Ramírez vs. Guatemala. S.C. (09.05.2008), párr. 63; Fernández Ortega y otros vs. México (2010), párr. 237, remitiéndose a los párr. 239 y 240; Rosendo Cantú y otra vs. México (2010), párr. 220, remitiéndose al párr. 222; Cabrera García y Montiel Flores vs. México (2010), párr. 233, remitiéndose al párr. 234; López Mendoza vs. Venezuela (2011), párr. 228, remitiéndose al párr. 225; Masacres de El Mozote y lugares aledaños vs. El Salvador (2012), párr. 318, 319 y punto resolutivo cuarto; Órdenes Guerra y otros vs. Chile (2018), párr. 128; Mendoza y otros vs. Argentina (2013), párr. 232; Rochac Hernández y otros 
Americana y los fallos de esta Corte sobre la normatividad interna, interpretaciones y prácticas que obstruyan el cumplimiento de lo dispuesto en un determinado caso"111.

Por lo mismo, "la Corte recuerda que cuando existe cosa juzgada internacional el 'control de convencionalidad' posee un importante rol en el cumplimiento o implementación de la Sentencia de la Corte Interamericana, un control dinámico y complementario de convencionalidad también posee un rol importante en el cumplimiento o implementación de una determinada Sentencia de la Corte Interamericana, especialmente cuando dicho acatamiento queda a cargo de los jueces nacionales. Bajo este supuesto, el órgano judicial tiene la función de hacer prevalecer la Convención Americana y los fallos de esta Corte sobre la normatividad interna, interpretaciones y prácticas que obstruyan el cumplimiento de lo dispuesto en un determinado caso"112.

Es por eso que en más de una oportunidad la Corte ha alabado lo que considera un uso correcto del control de convencionalidad por parte de las autoridades locales ${ }^{13}$, algunas veces refiriéndose específicamente a los jueces internos ${ }^{14}$, puesto que "en el sistema interamericano, existe un control dinámico y complementario de las obligaciones convencionales de los Estados de respetar y garantizar los derechos humanos, conjuntamente entre las autoridades internas (primariamente obligadas) y las instancias internacionales (en forma complementaria), de modo

vs. El Salvador (2014), párr. 213; Radilla Pacheco, Fernández Ortega y otros, y Rosendo Cantú y otra vs. México. S.C. (2015), párr. 21.

111 Gomes Lund y otros ("Guerrilha do Araguaia”) vs. Brasil. S.C. (2014), párr. 19, énfasis añadido. La misma idea en Apitz Barbera y otros vs. Venezuela. S.C. (2012), párr. 26; Gelman vs. Uruguay. S.C. (2013), párr. 73; Comunidad Moiwana vs. Surinam. S.C. (2018), párr. 12.

112 Masacres de Río Negro y Gudiel Álvarez y otros vs. Guatemala. S.C. (2014), párr. 16, énfasis añadido. La misma idea también en Masacres de Ituango vs. Colombia. S.C. (2013), párr. 30; Gelman vs. Uruguay. S.C. (2013), párr. 73; Apitz Barbera y otros vs. Venezuela. S.C. (2012), párr. 26. Por negación, 12 Casos Guatemaltecos vs. Guatemala. S.C. (2015), párr. 86 y 14.

113 Pollo Rivera y otros vs. Perú. Solicitud de Interpretación (2017), párr. 15; Andrade Salmón vs. Bolivia (2016), párr. 100 y 102; Tenorio Roca y otros vs. Perú (2016), párr. 231; Cabrera García y Montiel Flores vs. México. S.C. (2015), pár. 22; García Cruz y Sánchez Silvestre vs. México (2013), párr. 91; Castañeda Gutman vs. México. S.C. (2013), párr. 21-22; Uzcátegui y otros vs. Venezuela (2012), párr. 148; Asunto Pueblo indígena Kankuamo respecto de Colombia. Medida Provisional (2011), párr. 31; Asunto de las Penitenciarías de Mendoza respecto de Argentina. Medida Provisional (2011), párr. 40; Zambrano Vélez y otros vs. Ecuador. S.C. (2009), párr. 42; Gelman vs. Uruguay (2011), párr. 239.

114 Tenorio Roca y otros vs. Perú (2016), párr. 231; García Cruz y Sánchez Silvestre vs. México (2013), párr. 91; Castañeda Gutman vs. México. S.C. (2013), párr. 27; Zambrano Vélez y otros vs. Ecuador. S.C. (2009), párr. 42; Órdenes Guerra y otros vs. Chile (2018), párr. 101, 131 y 133. 
que los criterios de decisión, y los mecanismos de protección, tanto los nacionales como los internacionales, puedan ser conformados y adecuados entre sí"115.

Por iguales razones, la Corte ha reprochado en más de una ocasión que los jueces locales no hayan ejercido el control de convencionalidad y hayan aplicado leyes contrarias a lo establecido por sus sentencias ${ }^{16}$ (que por tanto, siguen vigentes).

De esta manera y al margen de las palabras usadas, lo común a todos las resoluciones analizadas en este epígrafe es que la Corte reconoce que la norma contraria a su parecer sigue existiendo, o si se prefiere, que no queda "anulada" o "destruida" en virtud de su propia sentencia. Es por eso que llama a las autoridades nacionales a realizar el control de convencionalidad y primeramente a los jueces, ordenándoles inaplicarla ${ }^{117}$, pese a que técnicamente sigue vigente. La frase "no vuelva a representar un obstáculo" ${ }^{118}$, sobre todo para la investigación de los hechos violatorios de los derechos humanos en juego, es tal vez la prueba más elocuente de ello.

Es por eso que la Corte reconoce que los órganos internos son absolutamente necesarios para "dejar sin efecto" las normas inconvencionales ${ }^{119}$. Por lo mismo y según se ha dicho, el ejercicio del control de convencionalidad en general posee

115 Andrade Salmón vs. Bolivia (2016), párr. 94, énfasis añadido. Ideas similares en Masacre de Santo Domingo vs. Colombia (2012), párr. 143; Vereda La Esperanza vs. Colombia (2017), párr. 261; Gelman vs. Uruguay. S.C. (2013), párr. 71 y 87-88; Masacres de Ituango vs. Colombia. S.C. (2013), párr. 30.

116 Barrios Altos y La Cantuta vs. Perú. S.C. (2018), párr. 65; Masacre de las Dos Erres vs. Guatemala (2009), párr. 131; Herzog y otros vs. Brasil (2018), párr. 311; Fontevecchia y D 'Amico vs. Argentina. S.C. (2017), párr. 25; Gomes Lund y otros ("Guerrilha do Araguaia") vs. Brasil. S.C. (2014), párr. 16, 18 y 19; Masacres de Río Negro y Gudiel Álvarez y otros vs. Guatemala. S.C. (2014), párr. 17; Masacres de Ituango vs. Colombia. S.C. (2013), párr. 30; Chitay Nech y otros vs. Guatemala. S.C. (2013), considerandos 12, 13 y 14; Gelman vs. Uruguay. S.C. (2013), párr. 90; Gomes Lund y otros ("Guerrilha do Araguaia”) vs. Brasil (2010), párr. 177.

117 Gomes Lund y otros ("Guerrilha do Araguaia") vs. Brasil. S.C. (2014), párr. 19, énfasis añadido. La misma idea en Radilla Pacheco, Fernández Ortega y otros, y Rosendo Cantú y otra vs. México. S.C. (2015), párr. 21; El Mozote y lugares aledaños vs. El Salvador. S.C. (2017), párr. 7; Rochac Hernández y otros vs. El Salvador (2014), párr. 213; Masacres de El Mozote y lugares aledaños vs. El Salvador (2012), párr. 318; López Mendoza vs. Venezuela (2011), párr. 228, remitiéndose al párr. 225; Chocrón Chocrón vs. Venezuela (2011), párr. 172; Cabrera García y Montiel Flores vs. México (2010), párr. 233; Rosendo Cantú y otra vs. México (2010), párr. 220; Fernández Ortega y otros vs. México (2010), párr. 237.

118 Véase nota 74.

119 Norín Catrimán y otros (Dirigentes, miembros y activista del pueblo indígena mapuche) vs. Chile (2014), párr. 436; Liakat Ali Alibux vs. Suriname (2014), párr. 151; Raxcacó Reyes vs. Guatemala. (09.05.2008), párr. 63. Por negación, Omar Humberto Maldonado Vargas y otros vs. Chile (2015), párr. 113; Fontevecchia y D 'Amico vs. Argentina. S.C. (2017), párr. 25. 
un importante papel en el cumplimiento o implementación de las sentencias de la Corte ${ }^{120}$.

Finalmente, el ejercicio del control de convencionalidad evita que el Estado caiga en responsabilidad internacional ${ }^{121}$, lo que explica que este tribunal alabe al país cuando lo ha llevado a cabo ${ }^{122}$.

\section{Algunas reflexiones a partir del análisis realizado}

A nuestro juicio, la principal consecuencia que puede extraerse luego del análisis realizado en los epígrafes anteriores, es que para tener reales efectos en la práctica, el control de convencionalidad externo resulta absolutamente dependiente del control de convencionalidad interno que hagan las diversas autoridades locales. Ello, porque la Corte Interamericana no posee la facultad inaplicar, invalidar o expulsar normas de un ordenamiento jurídico nacional. Esta labor recae, según se ha dicho, en los órganos nacionales, primeramente en el poder judicial, de acuerdo a lo señalado por este tribunal. Mas lo importante es que la norma objetada, por mucho que se señale que "carece de efectos", incluso "desde un inicio", en la práctica sigue existiendo, dependiendo su destino de lo que hagan las instancias domésticas.

De ahí que como ha declarado este mismo tribunal, la inconvencionalidad subsista mientras permanezca vigente la norma objetada, por mucho que el juez local la haya inaplicado en algunos casos mediante el control de convencionalidad interno. Esta y no otra es la razón por la cual, y coherentemente con ello, la Corte exija que esta norma sea "modificada, derogada, o anulada, o reformada"123, según se ha visto, pues teme que ella pueda ser utilizada nuevamente en el futuro. Todo lo cual vuelve a demostrar que dicha norma sigue existiendo.

No obstante, esta exigencia que la Corte hace a las autoridades locales ha sido criticada en atención a lo impreciso de su nomenclatura:

"Mención especial merece la curiosa posición de la Corte acerca de los efectos del control de convencionalidad en su faceta 'no interpretativa'. Anular, invalidar e inapli-

120 Gomes Lund y otros ("Guerrilha do Araguaia") vs. Brasil. S.C. (2014), párr. 19; Anzualdo Castro vs. Perú. S.C. (2013), párr. 24; Gelman vs. Uruguay. S.C. (2013), párr. 68.

121 Masacre de Santo Domingo vs. Colombia (2012), párr. 144; García Ibarra y otros vs. Ecuador (2015), párr. 103; Gelman vs. Uruguay. S.C. (2013), párr. 72; Apitz Barbera y otros vs. Venezuela. S.C. (2012), párr. 26. 122 Andrade Salmón vs. Bolivia (2016), párr. 102; Masacres de Ituango vs. Colombia. S.C. (2013), párr. 30. 123 Vid nota 93. 
car son efectos jurídicos que obedecen a circunstancias completamente disímiles que revelan clases diversas de anomalías normativas o distintos regímenes de invalidación. Problema crítico, pues un control normativo ha de generar certeza en la depuración que efectúe sobre sus prescripciones subordinadas, no ambivalencia conceptual ni fáctica."124

Por iguales razones -es decir, seguir existiendo, pese al control de convencionalidad externo-, la Corte ha señalado que dicha norma "no puede seguir representando un obstáculo" ${ }^{125}$ para la aplicación del tratado y para la protección de los derechos humanos.

Así entonces, puede concluirse que al aplicar únicamente el control externo de convencionalidad, la norma objetada permanece incólume.

El mismo razonamiento explica que la Corte emita de forma permanente supervisiones de cumplimiento, pues uno de los reproches más comunes que hace a los Estados es no haber realizado las modificaciones legales ordenadas en la sentencia, lo que incluye la derogación de las normas impugnadas en razón de su inconvencionalidad.

Según se ha dicho, el control de convencionalidad externo decretado por la Corte pretende que primeramente el control interno sea llevado a cabo por los jueces locales, ordenándoles inaplicar la norma en entredicho y en subsidio y de forma posterior, se dirige a los poderes creadores de normas. Por iguales razones, en varias supervisiones de cumplimiento se ha reprochado también a los jueces no haberlo hecho.

En este sentido, pues, la actuación del juez llamado a inaplicar las normas inconvencionales viene a ser una especie de atajo, o si se prefiere, una medida de emergencia para intentar solucionar el problema detectado por este tribunal internacional, a la espera que las autoridades creadoras de normas hagan lo suyo.

Mal puede ser así el control de convencionalidad externo, un "rayo exterminador" de normas locales, como se ha señalado alguna vez cuando recién comenzaba a meditarse a su respecto ${ }^{126}$. A decir verdad, el único efecto real que produce la declaración de inconvencionalidad decretada por la Corte es la responsabilidad internacional del Estado, no la abrogación de sus normas impugnadas; y

124 Henríquez y NúÑEZ (2016), 339, énfasis añadido.

125 Vid nota 74.

126 SAGÜÉs (s/f a), p. 464. 
en caso de subsistir dichas normas, una nueva declaración en tal sentido y así sucesivamente.

En realidad, todo lo señalado en el presente epígrafe podría ser visto desde la óptica inversa, en cuanto a que nada de lo dicho hasta aquí tendría sentido si las normas declaradas inconvencionales por la Corte fueran expulsadas automáticamente del ordenamiento interno, pues serían medidas innecesarias: no se requeriría la actuación de los jueces para que las “inaplicaran"127; ni la intervención posterior de los poderes ejecutivo o legislativo para derogar las normas cuestionadas; ni finalmente, tampoco tendrían sentido las críticas que sobre ambas actuaciones continua realizando la Corte en sus supervisiones de cumplimiento.

En suma, si el control de convencionalidad externo fuera realmente un "rayo exterminador" de normas incompatibles con los criterios de la Corte Interamericana, el control de convencionalidad interno no existiría, pues no tendría razón de ser. Sería innecesario, en razón que la norma ya habría sido "destruida" o eventualmente modificada por el primero. Por eso concluíamos que el control externo depende absolutamente del interno para tener efectos, salvo para determinar la existencia de responsabilidad internacional del Estado, según se ha dicho y se comentará más adelante.

Es por eso que algún país ha sido condenado en más de una oportunidad por aplicar las mismas leyes declaradas inconvencionales en un control de convencionalidad externo anterior (por ejemplo, leyes de amnistía), precisamente por no aplicarse el control de convencionalidad interno, obligando a este tribunal a decretar nuevamente el primero ${ }^{128}$. Mas con esto se vuelve otra vez al principio, pues igual que la primera vez, se requiere de la actuación de las autoridades nacionales (y así sucesivamente).

Por análogas razones, ciertos autores han señalado que existe cierta incompatibilidad entre la teoría del control de convencionalidad y el art. 2 de la Convención. Ello, pues si el control externo tuviera los efectos directos que algunos pretenden, sería en parte innecesario tener que modificar la legislación interna, al menos respecto de la derogación de las normas declaradas incompatibles, pues ello ya se habría producido automáticamente en virtud de dicho control. Con lo cual, varias de las recriminaciones que la Corte hace en sus supervisiones de cumplimiento carecerían de sentido. Como se ha señalado a este respecto:

127 Respecto de la labor de los jueces, Mejía (2014), p. 138.

128 Tenorio Roca y otros vs. Perú (2016), párr. 218-219. Vid nota 36. 
"Sin embargo, ninguno de estos controles tiene un firme fundamento jurídico en la CADH. La declaración directa de la Corte Interamericana que normas nacionales 'carecen de efectos jurídicos' - de carácter supranacional-contraviene el artículo 20. de la CADH, que establece la obligación de los Estados de adecuar su legislación interna a los parámetros de la $C A D H$. La referencia de la Corte Interamericana del artículo 27 de la CVDT -que ningún Estado puede justificar el incumplimiento de un tratado internacional con una norma de derecho interno no parece totalmente pertinente, en la medida en que el artículo 27 de la CVDT está dirigido a las relaciones interestatales. Una violación de la CADH en contravención con el artículo 27 de la CVDT implica responsabilidad estatal, pero una violación del artículo 27 de la CVDT no tiene, como tal, consecuencias para la validez de normas internas que contravienen una obligación internacional" ${ }^{129}$.

Por tanto, en el fondo lo que ocurre es que la Corte sólo dice lo que desde su perspectiva debe ocurrir, no lo que pasa necesariamente al interior del ordenamiento del país condenado. O si se prefiere, señala lo que punto de vista "debe ser", dependiendo absolutamente de la labor de las autoridades internas que llegue a convertirse en "ser". Ello porque la Corte no tiene modo de imponer sus fallos, lo que también explica el creciente aumento de supervisiones de cumplimiento que ha dictado en los últimos años. El control de convencionalidad externo vendría a ser así un deber, no un hecho, mostrando de esta manera la clara diferencia entre ordenar hacer algo y hacerlo por sí mismo.

Por iguales razones, aunque se diga que la Corte tiene la última palabra para calificar si el control de convencionalidad interno ha sido realizado correctamente, se requiere nuevamente de un control interno para ser llevado a la práctica, sin el cual quedará en las meras buenas intenciones.

En consecuencia, a nuestro juicio, el único efecto real del control de convencionalidad externo es que la norma no es considerada válida -o al menos aplicable-por la propia Corte, nada más. Para todo el resto requiere del control interno. Por tanto, el control externo es sólo un mecanismo que usa la Corte para determinar si existe o no compatibilidad entre la normativa interna y la Convención Americana y su jurisprudencia ${ }^{130}$. Constatada dicha incompatibilidad, ordena al Estado actuar para que su decisión tenga efectos.

Por eso es necesario recalcar, según se ha señalado más arriba, que la responsabilidad internacional solo implica que el estado ha infringido sus compromisos

129 Binder (2010), p. 173, énfasis añadido. Argumentos en parte similares en DulitzKy (2015), p. 60. 130 Nogueira (2012b), p. 1168; Rey Cantor y Rey Amaya (2014), p. 240. 
internacionales y que debe responder por ello. Pero per se, no anula ni expulsa la norma interna inconvencional, ni tampoco significa que de suyo cambie el modo de interpretarla (tema que no es analizado aquí); estos son actos propios del Estado, que podría continuar manteniéndola y asumir los costos de seguir siendo condenado como responsable internacionalmente. A lo sumo añadiría una nueva responsabilidad internacional, y así sucesivamente. Además, dicha responsabilidad sólo la puede declarar un tribunal internacional, no el juez local, como a veces pareciera insinuar cierta doctrina, sobre todo al señalar que al aplicar el control de convencionalidad interno, evita que el país caiga en este ilícito ${ }^{131}$.

\section{Conclusiones}

La pregunta sobre los efectos que produce al interior de un ordenamiento jurídico la declaración de inconvencionalidad total de alguna de sus normas decretada por la Corte Interamericana de Derechos Humanos -y que no permite una "interpretación conforme"-, ha recibido una respuesta dispar por parte de la doctrina, lo que además se manifiesta en la notable heterogeneidad de la nomenclatura utilizada. Para intentar aclarar este punto, se ha procedido a agrupar sus aseveraciones en una teoría "fuerte" y otra "débil" respecto de dichos efectos.

Del análisis de la jurisprudencia emanada de este tribunal, tanto de sus sentencias definitivas como supervisiones de cumplimiento, se desprende claramente que la norma inconvencional incompatible con sus criterios continúa existiendo, permaneciendo incólume, sin que se produzcan sobre la misma los efectos directos que alguna doctrina pareciera insinuar. Por tanto, el destino de esta norma depende de lo que hagan las autoridades locales a su respecto. Es así como la Corte llama a actuar primeramente a los jueces domésticos, ordenándoles inaplicar la norma impugnada, la cual al seguir existiendo, debiera ser posteriormente modificada o derogada por las autoridades competentes, al punto que mientras esto no ocurra, subsiste la inconvencionalidad decretada.

Lo anterior significa que la declaración de inconvencionalidad externa de la Corte sólo da origen a la responsabilidad internacional del Estado, en virtud de no cumplir con sus compromisos internacionales, pero no a la expulsión o inaplicación automática de la norma cuestionada; y en caso de no ejercerse el control de convencionalidad interno, puesto que las normas impugnadas continúan exis-

131 Vid nota 59. 
tiendo, sólo se añade una nueva responsabilidad internacional para el país condenado, y así sucesivamente.

En consecuencia, para tener efectos, el control de convencionalidad externo depende absoluta y totalmente de la puesta en marcha del control de convencionalidad interno, al punto que si el primero tuviera los efectos directos y automáticos que pareciera insinuar cierta doctrina, este último no tendría razón de ser. Lo anterior se prueba entre otras cosas, debido a las abundantes supervisiones de cumplimiento que dicta la Corte Interamericana, pues si las normas impugnadas fueran eliminadas automáticamente, estas resoluciones en buena medida carecerían de sentido. Por lo mismo, en alguna oportunidad un país ha sido condenado más de una vez por aplicar la misma norma declarada antes inconvencional por este tribunal internacional.

Lo anterior ha hecho que ciertos autores estimen que existe cierta incompatibilidad entre el control de convencionalidad externo y el artículo 2 de la Convención Americana sobre Derechos Humanos.

Finalmente, puede concluirse que el real efecto del control de convencionalidad externo, además de producir la responsabilidad internacional del Estado, es sólo la declaración de incompatibilidad entre las normas nacionales y lo dictaminado por la Corte. De ahí que este control sólo señale lo que desde la perspectiva de este tribunal, debe ser, dependiendo absolutamente de las autoridades internas que pase a convertirse en realidad. Ello, porque es muy distinto ordenar hacer algo que realizarlo por sí mismo.

\section{Bibliografía citada}

Aguilar Cavallo, Gonzalo (2016a): "Constitucionalismo global, control de convencionalidad y el derecho a huelga en Chile”, Anuario Colombiano de Derecho Internacional (ACDI) (Vol. 9), pp. 113-166.

Aguilar Cavallo, Gonzalo (2016b): "Los derechos humanos como límites a la democracia a la luz de la jurisprudencia de la Corte Interamericana de Derechos Humanos", Revista da AJURIS, Porto Alegre (Vol. 43 No 141), pp. 337-365. Aguilar Cavallo, Gonzalo; Nogueira Alcalá, Humberto (2016): "El principio favor persona en el derecho internacional y en el derecho interno como regla de interpretación y de preferencia normativa", Revista de Derecho Público (Vol. 84), pp. 13-43. 
BAZÁn, Víctor (2017): "Estado constitucional y convencional y protección de derechos humanos: Control de convencionalidad y diálogo interjurisdiccional", Revista Temas Socio Jurídicos (Vol. $36 \mathrm{~N}^{\circ}$ 72), pp. 13-37.

BAzÁN, Víctor (2010): "En torno al control de las inconstitucionalidades e inconvencionalidades omisivas", Anuario de Derecho Constitucional Latinoamericano (Año XVI, Montevideo), pp. 151-177.

Becerra Ramírez, Manuel (2013): "Control de convencionalidad (derecho internacional)”, Álvarez Ledesma, Mario I.; Cippitani, Roberto (Coord.), Diccionario Analítico de Derechos Humanos e Integración Jurídica (Roma, Peruggia, México, ISEG), pp. 88-92.

Binder, Christina (2010): “ ¿Hacia una Corte Constitucional de América Latina? La jurisprudencia de la Corte Interamericana de Derechos Humanos con un enfoque especial sobre las amnistías", Bogdandy, Armin von; Ferrer Mac-Gregor, Eduardo; Morales Antoniazzi, Mariela (Coords.), La justicia constitucional y su internacionalización. ¿Hacia un ius constitutuonale commune en América Latina? (traducc. Gonzalo Aguilar Cavallo y Rébecca Stewart, México, Unam; Max-Plank-Institut für a Usländisches ö Ffentliches Recht und Volkerrecht; Instituto Iberoamericano de Derecho Constitucional), Tomo II, pp. 159-188.

Burgorgue-Larsen, Laurence (2014): "La Corte Interamericana de Derechos Humanos como Tribunal Constitucional", Von Bogdandy, Armin; Fix-FieRro, Héctor; Morales Antoniazzi, Mariela (Coord.), Ius Constitutionale Commune en América Latina. Rasgos, Potencialidades y Desafíos (México, UNAM/Max-Planck-Institut Für Ausländisches/Öffentliches Recht Und Völkerrecht/Instituto Iberoamericano de Derecho Constitucional), pp. 421-457. CARbonell, Miguel (s/f), "Introducción general al control de convencionalidad", pp. 67-95. [Fecha de consulta: 14 de mayo de 2014]. [Disponible en http://biblio.juridicas.unam.mx/libros/7/3271/11.pdf].

Carvajal Martínez, Jorge; Guzmán Rincón, Andrés (2017): “Las instituciones del Sistema Interamericano de Protección a los derechos humanos: un análisis a sus procedimientos y orientación estratégica”, Revista Republicana (Núm. 22), pp. 183-207.

Castilla, Juárez, Karlos (2016): “Control de convencionalidad interamericano: Una propuesta de orden ante diez años de incertidumbre", Revista IIDH (Vol. 64), pp. 87-125. 
Castilla Juárez, Karlos (2013): “¿Control interno o difuso de convencionalidad? Una mejor idea: la garantía de los tratados", Anuario Mexicano de Derecho Internacional (vol. XIII), pp. 51-97.

Castro Córdoba, Harry et al (2017): “Dilemas de aplicación y eficacia del control de convencionalidad en el derecho doméstico", Summa Iuris, Medellín (vol. 5), pp. 38-61.

Contreras Vásquez, Pablo (2014): "Control de convencionalidad, deferencia internacional y discreción nacional en la jurisprudencia de la Corte Interamericana de Derechos Humanos", Ius et Praxis (Año 20 No 2), pp. 235-274.

Dulitzky, Ariel E. (2015): "An Inter-American Constitutional Court? The Invention of the Conventionality Control by the Inter-American Court of Human Rights", Texas International Law Journal (vol. 50, Issue 1), pp. 45-93.

Dulitzky, Ariel E. (2014): "El impacto del control de convencionalidad. ¿Un cambio de paradigma en el sistema interamericano de derechos humanos?", Rivera, Julio César; Elías, José Sebastián; Grosman, Lucas, Sebastián; LeGARre, Santiago; (Dir.), Tratado de los derechos constitucionales (Buenos Aires, Abeledo Perrott), pp. 533-569.

Escobar Fornos, Iván (2014): "La revolución de los derechos humanos", Ето Cruz, Gerardo (Coord.), Treinta Años de la Jurisdicción Constitucional en Perú (Lima, Centro de Estudios Constitucionales), Tomo II, pp. 1089-1120.

Ferrer Mac-Gregor, Eduardo (2016a): "El Control de Convencionalidad en la jurispruden-cia de la Corte Interamericana de Derechos Humanos", Pereira de Oliveira Duarte, Fabiane; Bittencourt da Cruz, Fabrício; Dal Maso JARDim, Tarciso (coord.), Controle de Convencionaliade (Brasilia, Conslho Nacional de Justicça), pp. 13-34.

Ferrer MaC-Gregor, Eduardo (2016b): "El control de convencionalidad como un vehículo para el diálogo judicial entre la Corte Interamericana de Derechos Humanos y los tribunales de América", Anuario de Derecho Constitucional Latinoamericano (Año XXII), pp. 337-356.

Ferrer MaC-Gregor, Eduardo (2015): "Conventionality Control. The New Doctrine of the Inter-American Court of Human Rights", Symposium: The Constitutionalization of International Law in Latin America, en American Journal of International Law (ASIL) (vol. 109), pp. 93-99.

Ferrer Mac-Gregor, Eduardo (2014): "Control de convencionalidad (sede interna)”, Ferrer Mac-Gregor, Eduardo; Martínez Ramírez, Fabiola; Fi- 
gueroa Mejía, Giovanni A. (Coords.), Diccionario de Derecho Procesal Constitucional y Convencional (México, Unam, segunda edición), pp. 236-240.

Ferrer MaC-Gregor, Eduardo (2013): "Eficacia de la sentencia interamericana y la cosa juzgada internacional: vinculación directa hacia las partes (res judicata) e indirecta hacia los estados parte de la Convención Americana (res interpretata) (sobre el cumplimiento del caso Gelman vs. Uruguay)", Estudios Constitucionales (Año $11 \mathrm{~N}^{\circ} 2$ ), pp. 641-693.

Ferrer MAC-Gregor, Eduardo (2011a): "Interpretación conforme y control difuso de convencionalidad. El nuevo paradigma para el juez mexicano", CARBONell, Miguel; Salazar, Pedro (Eds.), Derechos humanos; un nuevo modelo constitucional (México, Unam), pp. 339-429.

Ferrer MaC-Gregor, Eduardo (2011b): "Reflexiones sobre el control difuso de convencionalidad. A la luz del Caso Cabrera García y Montiel Flores vs. México", Boletín Mexicano de Derecho Comparado, nueva serie (Año XLIV, núm. 131, mayo-agosto), pp. 917-967.

Ferrer MaC-Gregor, Eduardo (2010): "El control difuso de convencionalidad en el Estado constitucional”, pp. 151-188. [Fecha de consulta: 11 de marzo de 2015]. [Disponible en http://biblio.juridicas.unam.mx/libros/6/2873/9.pdf].

Ferrer Mac-Gregor, Eduardo; Pelayo Möller, Carlos María (2017): Las obligaciones generales de la Convención Americana sobre Derechos Humanos (Deber de respeto, garantía y adecuación de derecho interno) (México, Unam Instituto de Investigaciones Jurídicas / Comisión Nacional de los Derechos Humanos).

Fuenzalida Bascuñán, Sergio (2015): "La jurisprudencia de la Corte Interamericana de Derechos Humanos como fuente del derecho. Una revisión de la doctrina del «examen de convencionalidad»", Revista de Derecho (Valdivia) (Vol. XXVIII No 1), pp. 171-192.

García Belaúnde, Domingo (2015): "El control de convencionalidad y sus problemas", Pensamiento Constitucional ( $\mathrm{N}^{\circ} 2 \mathrm{O}$ ), pp. 135-160.

GARCía JARAmillo, Leonardo (2016): “De la «constitucionalización» a la cconvencionalización» del ordenamiento jurídico. La contribución a un ius constitutionale commune", Revista Derecho del Estado (No 36), pp. 131-166.

García Pino, Gonzalo (2014): "Preguntas esenciales sobre el control de convencionalidad difuso aplicables a Chile”, Nogueira Alcalá, Humberto (Coord.), La protección de los derechos humanos y fundamentales de acuerdo a la consti- 
tución y el Derecho Internacional de los Derechos Humanos (Santiago, Librotecnia), pp. 355-379.

García Pino, Gonzalo; Contreras Vásquez, Pablo (2014): Diccionario Constitucional Chileno, Santiago, Cuadernos del Tribunal Constitucional $\mathrm{N}^{\circ} 55$.

García Ramírez Sergio (2016): "Sobre el control de convencionalidad", Pensamiento Constitucional ( $\mathrm{N}^{\circ} 22$ ), pp. 173-186.

García Ramírez, Sergio (2015): “The Relationship between Inter-American Jurisdiction and States (National Systems): Some Pertinent Questions", Notre Dame Journal of International \& Comparative Law (Vol. 5, Issue 1), pp. 115-151.

García Ramírez, Sergio (2011): "El control judicial interno de convencionalidad”, IUS, Revista del Instituto de Ciencias Jurídicas de Puebla (Año V, No 28), pp. 123-159.

García SAYÁn, Diego (2009): “La recepción del Derecho Internacional de los Derechos Humanos y la jurisprudencia de la Corte Interamericana de Derechos Humanos", García Ramírez, Sergio; Castañeda Hernández, Mireya (coords.), Recepción nacional del Derecho Internacional de los Derechos Humanos y admisión de la competencia de la Corte Interamericana (México, Unam/ Secretaría de Relaciones Exteriores Corte Interamericana de Derechos Humanos), pp. 91-119.

Henríquez ViÑas, Miriam (2014): "La polisemia del control de convencionalidad interno", International Law, Revista Colombiana de Derecho Internacional (vol. 24), pp. 113-141.

Henríquez ViÑas, Miriam y NúñEZ, José Ignacio (2016): "El control de convencionalidad: ¿Hacia un no positivismo interamericano?”, Revista Boliviana de Derecho (No 21 ), pp. 326-339.

Hitters, Juan Carlos (2015): "Control de convencionalidad (adelantos y retrocesos)”, Estudios Constitucionales (Año 13 No1), pp. 125-162.

Hitters, Juan Carlos (2012): "El control de convencionalidad y el cumplimiento de las sen-tencias de la Corte Interamericana”, Estudios Constitucionales (Año $10 \mathrm{~N}^{\circ} 2$, pp. 535-574.

Hitters, Juan Carlos (2009): "Control de constitucionalidad y control de convencionalidad. Comparación (Criterios fijados por la Corte Interamericana de Derechos Humanos)", Estudios Constitucionales (Año 7 No 2), pp. 109-128.

Hitters, Juan Carlos (2008): “ ¿Son vinculantes los pronunciamientos de la Comisión y de la Corte Interamericana de Derechos Humanos? (control de cons- 
titucionalidad y convencionalidad)", Revista Iberoamericana de Derecho Procesal Constitucional ( $\mathrm{N}^{\circ}$ 10, julio-diciembre), pp. 131-156.

IвÁÑEz Rivas, Juana María (2017): Control de convencionalidad (México, Unam Instituto de Investigaciones Jurídicas / Comisión Nacional de los Derechos Humanos).

IVANSCHITZ BouRdegueR, Bárbara (2013): "Un estudio sobre el cumplimiento y ejecución de las sentencias de la Corte Interamericana de Derechos Humanos por el Estado de Chile", Estudios Constitucionales (Año 11 No 1), pp. 275-332.

JimÉnez García, Francisco (2010): "Activismo judicial en la evolución del Derecho Internacional: hacia la configuración de un incipiente orden público internacional", Agenda Internacional (Año XVII N 28), pp. 75-102.

Londoño Lázaro, María Cermelina (2010): "El principio de legalidad y el control de convencionalidad de las leyes; confluencias y perspectivas en el pensamiento de la Corte Interamericana de Derechos Humanos", Boletín Mexicano de Derecho Comparado, nueva serie (Año XLIII, núm. 128), pp. 761-814.

MALARINo, Ezequiel (2011): “Activismo judicial, punitivización y nacionalización. Tendencias antidemocráticas y antiliberales de la Corte Interamericana de Derechos Humanos", Grupo Latinoamericano de Estudios sobre Derecho Penal Internacional, Sistema Interamericano de Protección de los Derechos Humanos y Derecho Penal Internacional (Montevideo, Konrad-Adenauer-Stiftung), pp. 25-61.

Mejía Lemos, Diego Germán (2014): "On the "Control de Convencionalidad» Doctrine: a Critical Appraisal of the Inter-American Court of Human Rights' Relevant Case Law", Anuario Mexicano de Derecho Internacional (Vol. XIV), pp. 117-151.

Morales Antoniazzi, Mariela (2017): "Interamericanización como mecanismo del Ius Constitutionale Commune de derechos humanos en América Latina”, Von Bogdandy, Armin; Morales Antoniazzi, Mariela; Ferrer Mac-GreGOR, Eduardo (Coord.), Ius Constitutionale Commune en América Latina. Textos básicos para su comprensión (México, Instituto de Estudios Constitucionales del Estado de Querétaro / Max Planck Institute for Comparative Public Law and International Law), pp. 417-456.

Morales Antoniazzi, Mariela (2014): "El Estado abierto como objetivo del Ius Constitucionale Commune. Aproximación desde el impacto de la Corte Interamericana de Derechos Humanos", Von Bogdandy, Armin; Fix-Fierro, 
Héctor; Morales Antoniazzi, Mariela (Coord.), Ius Constitutionale Commune en América Latina. Rasgos, potencialidades y desafíos (México, UNAM / Max-Planck-Institut für Ausländisches Öffentliches Recht und Völkerrecht / Instituto Iberoamericano de Derecho Constitucional), pp. 265-299.

Nash Rojas, Claudio (2013): "Control de convencionalidad. Precisiones conceptuales u desafíos a la luz de la jurisprudencia de la Corte Interamericana de Derechos Humanos", Anuario de Derecho Constitucional Latinoamericano (Año XIX), pp. 489-509.

Nogueira Alcalá, Humberto (2013a): “Diálogo interjurisdiccional y control de convencionalidad entre los tribunales nacionales y la Corte Interamericana de Derechos Humanos en Chile", Anuario de Derecho Constitucional latinoamericano (Año XIX), pp. 511-553.

Nogueira Alcalá, Humberto (2013b): "El control de convencionalidad y el diálogo interjurisdiccional entre tribunales nacionales y Corte Interamericana de Derechos Humanos", Revista de Derecho Constitucional Europeo (Año 10 Núm. 19), pp. 221-270.

Nogueira Alcalá, Humberto (2012a): "El uso del derecho convencional internacional de los derechos humanos en la jurisprudencia del Tribunal Constitucional chileno en el período 2006-2010", en Revista Chilena de Derecho (Vol. 39 No 1 ), pp. 149-187.

Nogueira Alcalá, Humberto (2012b): "Los desafíos del control de convencionalidad del corpus iuris interamericano para las jurisdicciones nacionales", Boletín Mexicano de Derecho Comparado, Nueva serie (Año XLV, núm. 135), pp. 1167-1220.

Nogueira Alcalá, Humberto (2012c): “Diálogo interjurisdiccional, control de convencionalidad y jurisprudencia del Tribunal Constitucional en el período 2006-2011", en Estudios Constitucionales (Año 10 No 2), pp. 57-140.

Olano García, Hernán (2016): “Teoría del Control de Convencionalidad”, Estudios Constitucionales (Año 14 No 1), pp. 61-94.

PAúl DíAZ, Álvaro (2013): "La Corte Interamericana in vitro: notas sobre su proceso de toma de decisiones a propósito del caso Artavia", Revista Derecho Público Iberoamericano, Universidad del Desarrollo (Año $1 \mathrm{~N}_{2}{ }_{2}$ ), pp. 303-345.

Pérez Manrique, Ricardo (2016): "Control de convencionalidad. Análisis de jurispru-dencia”, Anuario de Derecho Constitucional Latinoamericano (Año XXII), pp. 409-420. 
Piovesan, Flavia (2014): “Ius Constitutionale Commune latinoamericano en derechos humanos e impacto del Sistema Interamericano: rasgos, potencialidades y desafíos", Von Bogdandy, Armin; Fix-Fierro, Héctor; Morales AntoNIAZzI, Mariela (Coord.), Ius Constitutionale Commune en América Latina Rasgos, potencialidades y desafíos (México, UNAM / Max-Planck-Institut für Ausländisches Öffentliches Recht und Völkerrecht / Instituto Iberoamericano de Derecho Constitucional), pp. 61-81.

Rey Cantor, Ernesto (2008): “Controles de convencionalidad de las leyes", Ferrer Mac-Gregor, Eduardo y Zaldívar Lelo de Larrea, Arturo (Coords.), La Ciencia del Derecho Procesal Constitucional. Estudios en homenaje a Héctor Fix Zamudio en sus cincuenta años como investigador del derecho, Vol. IX Derechos Humanos y Tribunales Internacionales (México, Unam, Instituto Mexicano de Derecho Procesal Constitucional, Marcial Pons), pp. 225-262.

Rey Cantor, Ernesto; Rey Amaya, Ángela Margarita (2014): "Control de convencionalidad, test de”, Ferrer MaC-Gregor, Eduardo; Martínez Ramírez, Fabiola; Figueroa Mejía, Giovanni A. (Coords.), Diccionario de Derecho Procesal Constitucional y Convencional (México, Unam, $2^{\mathrm{a}}$ ed.) pp. 240-242.

Risso Ferrand, Martín (2013): “Cumplimiento de la sentencia de la Corte Interamericana de Derechos Humanos en el caso Gelman. Después de la declaración de inconstitucionalidad de la Ley Interpretativa 18.831", Anuario de Derecho Constitucional Latinoamericano (Año XIX), pp. 639-653.

Rousset SIRI, Andrés (2016): “Control de convencionalidad sobre normas procesales convencionales", Revista IIDH (Vol. 64), pp. 33-57.

SAGÜÉs, Néstor P. (2016): "El Control de Convencionalidad en Argentina. ¿Ante las Puertas de la «Constitución Convencionalizada»?", Pereira de Oliveira Duarte, Fabiane; Bittencourt da Cruz, Fabrício; Dal Maso Jardim, Tarciso (coords.), Controle de Convencionaliade (Brasilia, Coneslho Nacional de Justiça), pp. 107-121.

SAGÜÉs, Néstor P. (2015a): "Notas sobre el control ejecutivo de convencionalidad", Anuario de Derecho Constitucional Latinoamericano (Año XXI), pp. 141-149.

SAGÜÉs, Néstor P. (2015b): "Las opiniones consultivas de la Corte Interamericana, en el control de convencionalidad", Pensamiento Constitucional ( $\left.\mathrm{N}^{\circ} 20\right)$, pp. 275-283. 
SAGÜÉs, Néstor P. (2014): "Nuevas fronteras del control de convencionalidad: el reciclaje del derecho nacional y el control legisferante de convencionalidad", Revista de Investigações Constitucionais, Curitiva (Vol. 1 No 2), pp. 23-32.

SAGüÉs, Néstor P. (2012): "Derecho internacional y derecho constitucional. Dificultades operativas del control de convencionalidad en el sistema interamericano", Ahrens, Helen (Comp.), El Estado de derecho en América Latina. Libro homenaje a Horst Schönbolhm (México DF, Konrad Adenauer Stiftung, e. v.) pp. 21-29.

SAGÜÉs, Néstor P. (2010): "Obligaciones internacionales y control de convencionalidad", Estudios Constitucionales (Año 8 No 1), pp. 117-136.

SAGÜÉs, Néstor P. (2009a): "El 'control de convencionalidad', en particular sobre las constituciones nacionales", La Ley, 19/02/2009, 1, pp. 1-7. [Fecha de consulta: o6 de marzo de 2015]. [Disponible en http://www.joseperezcorti.com.ar/Archivos/DC/Articulos/Sagues_Control_de_Convencionalidad_LL_2009.pdf].

SAGÜÉs, Néstor P. (2009b): "Notas sobre el poder constituyente irregular", Anuario de Derecho Constitucional Latinoamericano (Año XCV), pp. 151-163.

SAGÜÉs, Néstor P. (s/f a): "El «Control de convencionalidad» como instrumento para la elaboración de un ius commune interamericano", pp. 449-468. [Fecha de consulta: o7 de mayo de 2014]. [Disponible en http://biblio.juridicas.unam. $\mathrm{mx} / \mathrm{libros} / 6 / 2895 / 15 . \mathrm{pdf}]$.

SAGüÉs, Néstor P. ( $\mathrm{s} / \mathrm{f}$ b): “El 'control de convencionalidad' en el sistema interamericano y sus anticipos en el ámbito de los derechos económico-sociales. Concordancias y diferencias con el sistema europeo", pp. 381-417. [Fecha de consulta: 27 de marzo de 2014]. [Disponible en http://biblio.juridicas.unam. $\mathrm{mx} / \mathrm{libros} / 7 / 3063 / 16 . \mathrm{pdf}]$.

Silva Аввотт, Max (2018) “¿Es realmente viable el control de convencionalidad?", Revista Chilena de Derecho (Vol. 45 No 3), pp. 717-144.

Torelly, Marcelo (2017): “Controle de convencionalidade: ¿constitucionalismo regional dos direitos humanos?”, Revista Direito \& Práxis, Río de Janeiro (Vol. $8 \mathrm{~N}^{\circ} 1$ ), pp. 321-353.

Vio Grossi, Eduardo (2015): "Jurisprudencia de la Corte Interamericana de Derechos Humanos: ¿del control de convencionalidad a la supranacionalidad?", Anuario de Derecho Constitucional Latinoamericano (Año XXI), pp. 93-112. 


\section{Jurisprudencia citada de la Corte Interamericana de Derechos Humanos}

Órdenes Guerra y otros vs. Chile. Fondo, Reparaciones y Costas. 29 noviembre 2018. Serie C No 372.

Norín Catrimán y otros (Dirigentes, Miembros y Activista del Pueblo Indígena Mapuche) vs. Chile. S.C. 28 noviembre 2018.

Comunidad Moiwana vs. Surinam. S.C. 21 noviembre 2018.

Pueblo Saramaka vs. Surinam. S.C. 26 septiembre 2018.

Barrios Altos y La Cantuta vs. Perú. S.C. 30 mayo 2018.

Bueno Alves vs. Argentina. S.C. 30 mayo 2018.

Zegarra Marín vs. Perú. S.C. 30 mayo 2018.

Amrhein y otros vs. Costa Rica. Excepciones Preliminares, Fondo, Reparaciones y Costas. 25 abril 2018, Serie C No 354.

Herzog y otros vs. Brasil. Excepciones Preliminares, Fondo, Reparaciones y Costas. 15 marzo 2018. Serie $\mathrm{C} \mathrm{N}^{\circ} 353$.

Ramírez Escobar y otros vs. Guatemala. Fondo, Reparaciones y Costas. o9 marzo 2018. Serie C No 351.

Pueblo Indígena Xucuru y sus miembros vs. Brasil. Excepciones Preliminares, Fondo, Reparaciones y Costas. 05 febrero 2018. Serie C No 346.

Trabajadores Cesados de Petroperú y otros vs. Perú. Excepciones Preliminares, Fondo, Reparaciones y Costas. 23 noviembre 2017. Serie C No 344.

Heliodoro Portugal vs. Panamá. S.C. 14 noviembre 2017.

Vereda La Esperanza vs. Colombia. Excepciones Preliminares, Fondo, Reparaciones $y$ Costas. 31 agosto 2017. Serie $\mathrm{C} \mathrm{N}^{\circ} 341$.

Fontevecchia y D'Amico vs. Argentina. S.C. 18 octubre 2017.

Masacres de El Mozote y lugares aledaños vs. El Salvador. S.C. 31 agosto 2017.

Comunidades Indígenas Yakye Axa, Sawhoyamaxa y Xákmok Kásek vs. Paraguay.

S.C. 30 agosto 2017.

Kawas Fernández y Caso Luna López vs. Honduras. S.C. 30 agosto 2017.

Maldonado Ordóñez vs. Guatemala. S.C. 30 agosto 2017.

Pollo Rivera y otros vs. Perú. Solicitud de Interpretación de la Sentencia de Fondo,

Reparaciones y Costas. 25 mayo 2017. Serie C No 335.

Pacheco Teruel y otros vs. Honduras. S.C. 23 mayo 2017.

Velásquez Paiz y otros vs. Guatemala. S.C. 23 mayo 2017.

Goiburú y otros vs. Paraguay. S.C. 23 mayo 2017. 
Zegarra Marín vs. Perú. Excepciones Preliminares, Fondo, Reparaciones y Costas. 15 febrero 2017. Serie C No 331.

Penal Miguel Castro Castro vs. Perú. S.C. o9 febrero 2017.

Andrade Salmón vs. Bolivia. Fondo, Reparaciones y Costas.1 diciembre 2016.Serie $\mathrm{C} \mathrm{N}$ o 330 .

Miembros de la Aldea Chichupac y comunidades vecinas del Municipio de Rabinal vs. Guatemala. Excepciones Preliminares, Fondo, Reparaciones y Costas. 30 noviembre 2016. Serie C No 328.

Chocrón Chocrón, Díaz Peña, y Uzcátegui y otros vs. Venezuela. S.C. 22 noviembre 2016.

Pollo Rivera y otros vs. Perú. Fondo, Reparaciones y Costas. 21 octubre 2016.Serie C No 319.

Trabajadores de la Hacienda Brasil Verde vs. Brasil. Excepciones Preliminares, Fondo, Reparaciones y Costas. 20 octubre 2016. Serie C No 318.

Comunidades Indígenas Yakye Axa, Sawhoyamaxa y Xákmok Kásek vs. Paraguay.

S.C. 01 septiembre 2016.

Hermanas Serrano Cruz vs. El Salvador. S.C. o1 septiembre 2016.

Contreras y otros vs. El Salvador. S.C. o1 septiembre 2016.

Palamara Iribarne vs. Chile. S.C. o1 septiembre 2016.

Flor Freire vs. Ecuador. Excepción Preliminar, Fondo, Reparaciones y Costas. 31 agosto 2016. Serie $\mathrm{C} \mathrm{N}^{\mathrm{o}} 315$.

Chaparro Álvarez y Lapo Íñiguez vs. Ecuador. S.C. 23 junio 2016.

Tenorio Roca y otros vs. Perú. Excepciones Preliminares, Fondo, Reparaciones y Costas. 22 junio 2016. Serie C No 314.

Maldonado Ordoñez vs. Guatemala. Excepción Preliminar, Fondo, Reparaciones y Costas. 03 mayo 2016, Serie C No 311.

Chinchilla Sandoval vs. Guatemala. Excepción Preliminar, Fondo, Reparaciones y Costas. 29 febrero 2016. Serie $\mathrm{C} \mathrm{N}^{\circ} 312$.

12 Casos Guatemaltecos vs. Guatemala. S.C. 24 noviembre 2015.

Chocrón Chocrón, Díaz Peña, y Uzcátegui y otros vs. Venezuela. S.C. 20 noviembre 2015.

Yvon Neptune vs. Haití. S.C. 20 noviembre 2015.

Hilaire, Constantine y Benjamin y otros y Caesar vs. Trinidad y Tobago. S.C. 20 noviembre 2015.

Yatama vs. Nicaragua. S.C. 20 noviembre 2015. 
Ríos y otros, Perozo y otros y Reverón Trujillo vs. Venezuela. S.C. 20 noviembre 2015.

López Mendoza vs. Venezuela. S.C. 20 noviembre 2015.

El Amparo, Blanco Romero y otros, Montero Aranguren y otros, Barreto Leiva y Usón Ramírez vs. Venezuela. S.C. 20 noviembre 2015.

García Ibarra y otros vs. Ecuador. Excepciones Preliminares, Fondo, Reparaciones y Costas. 17 noviembre 2015. Serie C No 306.

Comunidad Garifuna de Punta Piedra y sus Miembros vs. Honduras. Excepciones Preliminares, Fondo, Reparaciones y Costas. o8 octubre 2015. Serie C No 304. López Lone y otros vs. Honduras. Excepción Preliminar, Fondo, Reparaciones y Costas. 05 octubre 2015. Serie C No 302.

Omar Humberto Maldonado Vargas y otros vs. Chile. Fondo, Reparaciones y Costas. 2 septiembre 2015. Serie C No 300.

Granier y otros (Radio Caracas Televisión) vs. Venezuela. Excepciones Preliminares, Fondo, Reparaciones y Costas. 22 junio 2015. Serie C No 293.

Heliodoro Portugal vs. Panamá. S.C. 19 junio 2012.

Penal Miguel Castro Castro vs. Perú. S.C. 17 abril 2015.

Cabrera García y Montiel Flores vs. México. S.C. 17 abril 2015.

García Lucero y otras vs. Chile. S.C. 17 abril 2015.

Radilla Pacheco, Fernández Ortega y otros y Rosendo Cantú y otra vs. México. S.C. 17 abril 2015.

Chaparro Álvarez y Lapo Íniguez vs. Ecuador. S.C. 27 enero 2015.

J. vs. Perú. Interpretación de la Sentencia de Excepción Preliminar, Fondo, Reparaciones y Costas. 20 noviembre 2014. Serie C No 291.

Osorio Rivera y familiares vs. Perú. Interpretación de la Sentencia de Excepciones Preliminares, Fondo, Reparaciones y Costas. 20 noviembre 2014. Serie C No 290. Gomes Lund y otros ("Guerrilha do Araguaia") vs. Brasil. S.C. 17 de octubre de 2014.

Rochac Hernández y otros vs. El Salvador. Fondo, Reparaciones y Costas. 14 octubre 2014. Serie C No 285.

Personas dominicanas y haitianas expulsadas vs. República Dominicana. Excepciones Preliminares, Fondo, Reparaciones y Costas. 28 agosto 2014. Serie C No 282. Hermanos Landaeta Mejías y otros vs. Venezuela. Excepciones Preliminares, Fondo, Reparaciones y Costas. 27 agosto 2014. Serie C No 281.

Masacres de Río Negro y Gudiel Álvarez y otros vs. Guatemala. S.C. 21 agosto 2014. 
Supervisión conjunta de 11 casos vs. Guatemala. S.C. 21 agosto 2014.

Norín Catrimán y otros (Dirigentes, miembros y activista del pueblo indígena mapuche) vs. Chile. Fondo, Reparaciones y Costas. 29 mayo 2014. Serie C No 279.

Liakat Ali Alibux vs. Suriname. Excepciones Preliminares, Fondo, Reparaciones y Costas. 30 enero 2014. Serie C No 276.

Osorio Rivera y Familiares vs. Perú. Excepciones Preliminares, Fondo, Reparaciones $y$ Costas. 26 noviembre 2013. Serie C No 274.

García Cruz y Sánchez Silvestre vs. México. Fondo, Reparaciones y Costas. 26 noviembre 2013. Serie C No 273.

Familia Pacheco Tineo vs. Bolivia. Excepciones Preliminares, Fondo, Reparaciones y Costas. 25 noviembre 2013. Serie C No 272.

Tribunal Constitucional (Camba Campos y otros) vs. Ecuador. Excepciones Preliminares, Fondo, Reparaciones y Costas. 28 agosto 2013. Serie C No 268.

Castañeda Gutman vs. México. S.C. 28 agosto 2013.

Yatama vs. Nicaragua. S.C. 22 agosto 2013.

Chitay Nech y otros vs. Guatemala. S.C. 22 agosto 2013.

Anzualdo Castro vs. Perú. S.C. 21 agosto 2013.

Masacres de Ituango vs. Colombia. S.C. 21 mayo 2013.

Mendoza y otros vs. Argentina. Excepciones Preliminares, Fondo y Reparaciones. 14 mayo 2013 Serie C No 260.

Radilla Pacheco vs. México. S.C. 14 mayo 2013.

Gelman vs. Uruguay. S.C. 20 marzo 2013.

Masacre de Santo Domingo vs. Colombia. Excepciones Preliminares, Fondo y Reparaciones. 30 noviembre 2012. Serie $\mathrm{C} \mathrm{No} 259$.

Apitz Barbera y Otros ("Corte Primera de lo Contencioso Administrativo") vs. Venezuela. S.C. 23 noviembre 2012.

Gudiel Álvarez y otros (Diario Militar) vs. Guatemala. Fondo Reparaciones y Costas. 20 noviembre 2012 Serie C No 253.

Masacres de El Mozote y lugares aledaños vs. El Salvador. Fondo, Reparaciones y Costas. 25 octubre 2012. Serie C No 252.

Nadege Dorzema y otros vs. República Dominicana. Fondo Reparaciones y Costas. 24 de octubre de 2012 Serie C No 251.

Uzcátegui y otros vs. Venezuela. Fondo y Reparaciones. 03 septiembre 2012. Serie C No 249 . 
Masacres de Río Negro vs. Guatemala. Excepción Preliminar, Fondo, Reparaciones $y$ Costas. 04 septiembre 2012 Serie C No 250.

Masacre de las Dos Erres vs. Guatemala. S.C. o4 septiembre 2012.

Furlan y Familiares vs. Argentina. Excepciones Preliminares, Fondo, Reparaciones y Costas. 31 agosto 2012. Serie C No 246.

Lori Berenson Mejía vs. Perú. S.C. 20 junio 2012.

Forneron e hija vs. Argentina. Fondo, Reparaciones y Costas. 27 abril 2012 Serie C No 242.

Atala Riffo y Niñas vs. Chile.Fondo, Reparaciones y Costas. 24 febrero 2012.Serie C No 239.

Fontevecchia y D 'Amico vs. Argentina. Fondo, Reparaciones y Costas. 29 noviembre 2011. Serie C No 238.

Pueblo Saramaka vs. Surinam. S.C. 23 noviembre 2011.

Blanco Romero y otros vs. Venezuela. S.C. 22 noviembre 2011.

Boyce y otros vs. Barbados. S.C. 21 noviembre 2011.

Niñas Yean y Bosico vs. República Dominicana. 10 octubre 2011.

Barrios Altos vs. Perú. S.C. 07 septiembre 2012.

López Mendoza vs. Venezuela. Fondo Reparaciones y Costas. o1 septiembre 2011 Serie C No 233.

Montero Aranguren y Otros (Retén de Catia) vs. Venezuela. S.C. 30 agosto 2011.

Torres Millacura y otros vs. Argentina. Fondo, Reparaciones y Costas. 26 agosto 2011. Serie C No 229.

Asunto Pueblo indígena Kankuamo respecto de Colombia. Medida Provisional. o7 julio 2011.

Bueno Alves vs. Argentina. S.C. 05 julio 2011.

Gómez Palomino vs. Perú. S.C. 05 julio 2011.

Chocrón Chocrón vs. Venezuela. Excepción Preliminar, Fondo, Reparaciones y Costas. 01 julio 2011. Serie C No 227.

Castillo Petruzzi y otros vs. Perú. S.C. 01 julio 2011.

Loayza Tamayo vs. Perú. S.C. o1 julio 2011.

Palamara Iribarne vs. Chile. S.C. o1 julio 2011.

Asunto de las Penitenciarías de Mendoza respecto de Argentina. Medida Provisional. o1 julio 2011.

Yatama vs. Nicaragua. S.C. 30 de junio de 2011.

Radilla Pacheco vs. México. S.C. 19 de mayo de 2011. 
Gelman vs. Uruguay. Fondo y Reparaciones. 24 febrero 2011 Serie C No 221.

Chaparro Álvarez y Lapo Íñiguez vs. Ecuador. S.C. 22 febrero 2011.

Cabrera García y Montiel Flores vs. México. Excepción Preliminar, Fondo, Reparaciones y Costas. 26 noviembre 2010 Serie C No 220.

Gomes Lund y otros ("Guerrilha do Araguaia”) vs. Brasil. Excepciones Preliminares, Fondo, Reparaciones y Costas. 24 noviembre 2010. Serie C No 219.

Vélez Loor vs. Panamá. Excepciones Preliminares, Fondo, Reparaciones y Costas. 23 noviembre 2010 Serie C No 218.

Bámaca Velásquez vs. Guatemala. S.C. 18 noviembre 2010.

Kimel vs. Argentina. S.C. 15 noviembre 2010.

Fernández Ortega y otros vs. México. Excepción Preliminar, Fondo, Reparaciones y Costas. 30 agosto 2010 Serie C No 215.

Ibsen Cárdenas e Ibsen Peña vs. Bolivia. Fondo, Reparaciones y Costas. 01 septiembre 2010 Serie C No 217.

Rosendo Cantú y otra vs. México. Excepción Preliminar, Fondo, Reparaciones y Costas. 31 agosto 2010 Serie C No 216.

Ivcher Bronstein vs. Perú. S.C. 27 agosto 2010.

Niñas Yean y Bosico vs. República Dominicana. S.C. 27 agosto 2010.

Comunidad Indígena Xákmok Kásek vs. Paraguay. Fondo, Reparaciones y Costas. 24 agosto 2010 Serie C No 214, 2010.

Yatama vs. Nicaragua. S.C. 28 mayo 2010.

Chaparro Álvarez y Lapo Íñiguez vs. Ecuador. S.C. 19 mayo 2010.

Yatama vs. Nicaragua. S.C. 21 abril 2010.

Masacre de las Dos Erres vs. Guatemala. Excepción Preliminar, Fondo, Reparaciones y Costas. 24 noviembre 2009. Serie C No 211.

“Cinco Pensionistas" vs. Perú. S.C. 24 noviembre 2009.

Ivcher Bronstein vs. Perú. S.C. 24 noviembre 2009.

Radilla Pacheco vs. México. Excepciones Preliminares, Fondo, Reparaciones y Costas. 23 noviembre 2009. Serie C No 209.

Barreto Leiva vs. Venezuela. Fondo, Reparaciones y Costas.17 noviembre 2009.Serie $\mathrm{C} \mathrm{N}^{\circ} 206$.

Montero Aranguren y Otros (Retén de Catia) vs. Venezuela. S.C. 17 noviembre 2009.

Dacosta Cadogan vs. Barbados. Excepciones Preliminares, Fondo, Reparaciones y Costas. 24 septiembre 2009. Serie C No 204. 
Anzualdo Castro vs. Perú. Excepción Preliminar, Fondo, Reparaciones y Costas. 22 septiembre 2009. Serie C No 202.

Zambrano Vélez y otros vs. Ecuador. S.C. 21 septiembre 2009.

Molina Theissen vs. Guatemala. S.C. 17 agosto 2009.

Ticona Estrada y otros vs. Bolivia. Interpretación de la Sentencia de Fondo, Reparaciones y Costas. 1 julio 2009 Serie C No 199.

Herrera Ulloa vs. Costa Rica. S.C. 02 junio 2009.

Blanco Romero y otros vs. Venezuela. S.C. 18 mayo 2009.

Niñas Yean y Bosico vs. República Dominicana. S.C. 18 mayo 2009.

Chaparro Álvarez y Lapo Íñiguez vs. Ecuador. S.C. 29 abril 2009.

Bámaca Velásquez vs. Guatemala. S.C. 27 enero 2009.

Bulacio vs. Argentina. S.C. 26 noviembre 2008.

Bámaca Velásquez vs. Guatemala. S.C. 11 noviembre 2008.

Heliodoro Portugal vs. Panamá. Excepciones Preliminares, Fondo, Reparaciones y Costas. 12 agosto 2008. Serie C No 186.

Castañeda Gutman vs. México. Excepciones Preliminares, Fondo, Reparaciones y Costas. 06 agosto 2008. Serie C No 184.

Raxcacó Reyes vs. Guatemala. S.C. o9 mayo 2008.

Salvador Chiriboga vs. Ecuador. Excepción Preliminar y Fondo. 6 mayo 2008.Serie C No 179.

Raxcacó Reyes vs. Guatemala y Fermín Ramírez vs. Guatemala. S.C. 28 marzo 2008.

Trabajadores Cesados del Congreso (Aguado Alfaro y Otros) vs. Perú. Solicitud de Interpretación de la Sentencia de Excepciones Preliminares, Fondo, Reparaciones y Costas. 30 Noviembre 2007 Serie C No 174.

Chaparro Álvarez y Lapo Íñiguez vs. Ecuador. Excepciones Preliminares, Fondo, Reparaciones y Costas. 21 noviembre 2007. Serie C No 170.

Boyce y otros vs. Barbados. Excepción Preliminar, Fondo, Reparaciones y Costas. 20 noviembre 2007. Serie C No 169.

Zambrano Vélez y otros vs. Ecuador. Fondo, Reparaciones y Costas. 04 julio 2007. Serie C No 166.

Comunidad Indígena Sawhoyamaxa vs. Paraguay. S.C. 02 febrero 2007.

La Cantuta vs. Perú. Fondo, Reparaciones y Costas. 29 noviembre 2006. Serie C No 162. 
Almonacid Arellano y otros vs. Chile. Excepciones Preliminares, Fondo, Reparaciones y Costas. 26 septiembre 2006. Serie C No 154.

Montero Aranguren y Otros (Retén de Catia) vs. Venezuela. Excepción Preliminar, Fondo, Reparaciones y Costas. 05 julio 2006. Serie C No 150.

Gómez Palomino vs. Perú. Fondo, Reparaciones y Costas 22 noviembre 2005.Serie C No 136.

Palamara Iribarne vs. Chile. Fondo, Reparaciones y Costas 22 noviembre 2005. Serie $\mathrm{C} \mathrm{N}^{\circ} 135$.

Raxcacó Reyes vs. Guatemala. Fondo, Reparaciones y Costas. 15 septiembre 2005. Serie C No 133.

Yatama vs. Nicaragua. Excepciones Preliminares, Fondo, Reparaciones y Costas. 23 junio 2005. Serie C No 127.

Fermín Ramírez vs. Guatemala. Fondo, Reparaciones y Costas. 20 junio 2005.Serie $\mathrm{C} \mathrm{N}^{\circ} 126$.

Comunidad Indígena Yakye Axa vs. Paraguay. Fondo Reparaciones y Costas. 17 junio 2005. Serie C No 125 .

Caesar vs. Trinidad y Tobago. Fondo, Reparaciones y Costas.11 marzo 2005.Serie C $\mathrm{N}^{\circ} 123$.

Hermanas Serrano Cruz vs. El Salvador. Fondo, Reparaciones y Costas. 1 marzo 2005. Serie C No 120.

Lori Berenson Mejía vs. Perú. Fondo, Reparaciones y Costas. 25 noviembre 2004. Serie C No 119.

"Instituto de Reeducación del Menor" vs. Paraguay. Excepciones Preliminares, Fondo, Reparaciones y Costas. 2 septiembre 2004. Serie C No 112.

Bámaca Velásquez vs. Guatemala. S.C. 27 noviembre 2003.

Bulacio vs. Argentina. Fondo, Reparaciones y Costas. 18 septiembre 2003. Serie C No 100.

“Cinco Pensionistas" vs. Perú. Fondo, Reparaciones y Costas 28 febrero 2003.Serie C No 98.

Barrios Altos vs. Perú. Interpretación de la Sentencia de Fondo. 03 septiembre 2001. Serie C No 83 .

Barrios Altos vs. Perú. Fondo. 14 marzo 2001. Serie C No 75.

Baena Ricardo y otros vs. Panamá. Fondo, Reparaciones y Costas. 02 febrero 2001, Serie C No 72.

Durand y Ugarte vs. Perú. Fondo. 16 agosto 200o. Serie No 68. 
Garrido y Baigorria vs. Argentina. Reparaciones y Costas 27 agosto 1998. Serie C No 39.

Velásquez Rodríguez vs. Honduras. Fondo. 29 julio 1988. Serie C oo 4. 